
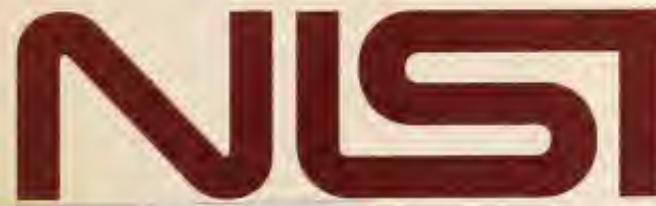

IIIIIUI

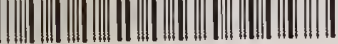

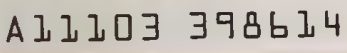

NIST

PUBLICATIONS

\section{UNITED STATES}

DEPARTMENT OF COMMERCE

NATIONAL INSTITUTE OF STANDARDS

AND TECHNOLOGY

NIST Technical Note 1336

\title{
Wavelength Measurement System for Optical Fiber Communications
}

Gregory E. Obarski

100

.05753

\#1336

1990

C.2 
NATIONAL INSTTTUTE OF STANDARDS \&

TECHNOLOGY

Research Information Center

.Gaithersburg, MD 20899

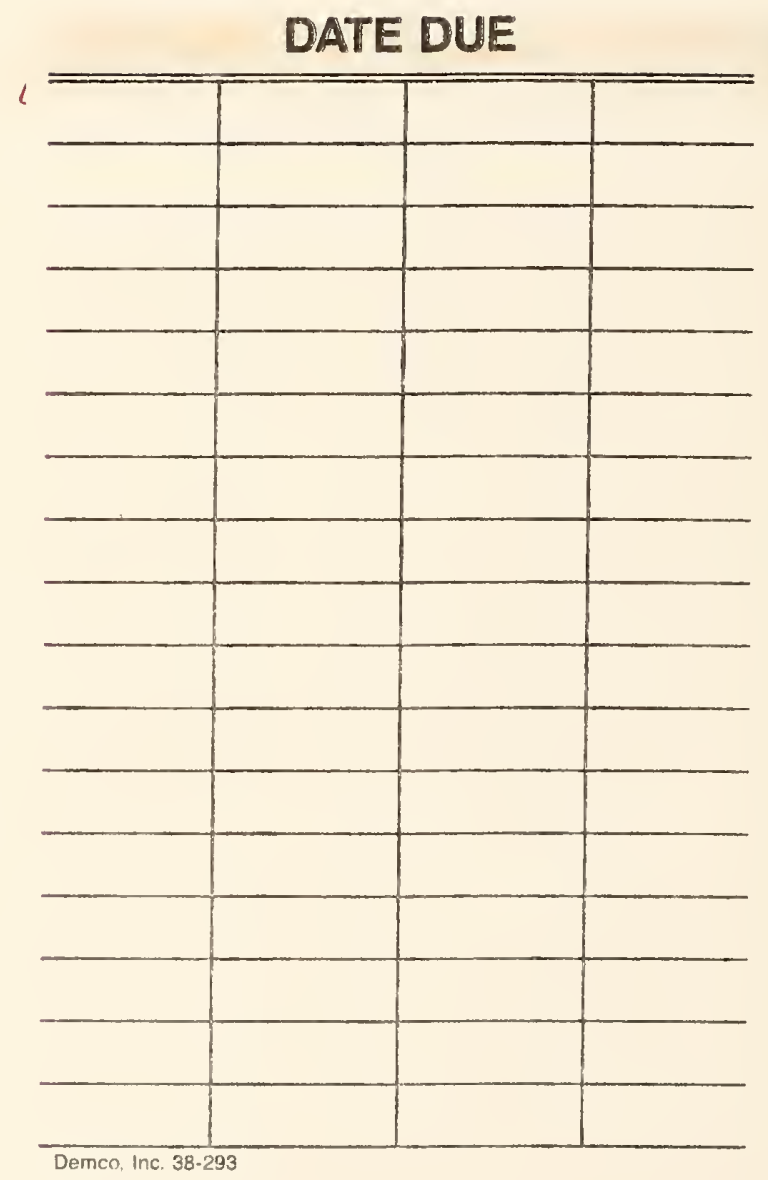




\title{
Wavelength Measurement System for Optical Fiber Communications
}

\author{
Gregory E. Obarski
}

Electromagnetic Technology Division

Center for Electronics and Electrical Engineering

National Engineering Laboratory

National Institute of Standards and Technology

Boulder, Colorado 80303-3328

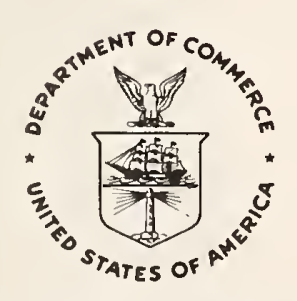

U.S. DEPARTMENT OF COMMERCE, Robert A. Mosbacher, Secretary NATIONAL INSTITUTE OF STANDARDS AND TECHNOLOGY, John W. Lyons, Director 


\section{National Institute of Standards and Technology Technical Note 1336 Natl. Inst. Stand. Technol., Tech. Note 1336, 44 pages (Feb. 1990) CODEN:NTNOEF}


1. Introduction. . . . . . . . . . . . . . . . . . . . . . 1

2. Background. . . . . . . . . . . . . . . . . 2

3. Principle of Lambdameter. . . . . . . . . . . . . . . 5

4. Accuracy and Resolution . . . . . . . . . . . . . . 6

4.1 Path Folding. . . . . . . . . . . . . . . 6

4.2 Dispersion of Air. . . . . . . . . . . . . . . 7

4.3 Diffraction. . . . . . . . . . . . . . . . 10

4.4 Colinearity of the Reference and Unknown Laser Beams . 11

4.5 Phase Uncertainty Between Recombining Beams. . . . . . 13

4.6 Other Potential Sources of Error . . . . . . . . . . 13

5. System Design. . . . . . . . . . . . . . . . 14

5.1 Optical Design. . . . . . . . . . . . . . . 14

5.2 Reference Laser. . . . . . . . . . . . . . . . . . . 17

5.3 Photodetectors and Fringe-Signal Frequency Multipliers.................. . . . 18

5.4 Instrumentation and Optical Components . . . . . . . . 19

5.5 Optical Alignment of the System. . . . . . . . . . . . 21

5.6 Measured Accuracy. . . . . . . . . . . . . . 22

6. Wavelength Measurements on a Single-Mode Diode Laser Source. . . . . . . . . . . . . . . . . . 24

6.1 Description of the $1.52 \mu \mathrm{m}$ Diode Laser . . . . . . . . 24

6.2 Results of Wavelength Measurements . . . . . . . . 25

7. Discussion and Conclusions. . . . . . . . . . . . . . . . 31

8. Acknowledgments . . . . . . . . . . . . . . . . . . 31

9. References. . . . . . . . . . . . . . . . . 31

Appendix A. Raw Data From Diode Laser Wavelength Measurements . 35

Appendix B. Optical Designs for Lambdameters. . . . . . . . . . 36

Appendix C. First-Generation System . . . . . . . . . . . . . . 39 

WAVELENGTH MEASUREMENT SYSTEM FOR OPTICAL FIBER COMMUNICATIONS

\author{
Gregory E. Obarski \\ Electromagnetic Technology Division \\ National Institute of Standards and Technology \\ Boulder, CO 80303
}

\begin{abstract}
A wavelength measurement system (lambdameter) for singlemode sources used in optical fiber communications is described. The sources of interest are mainly diode lasers emitting at 1.3 and $1.5 \mu \mathrm{m}$, but the system can be used in the near IR and red regions of the spectrum. Accuracy in wavelength measurement is $<0.1 \mathrm{ppm}$ at the $0.63 \mu \mathrm{m}$ HeNe line by comparing separately each of two adjacent modes from a HeNe laser that is frequencystabilized by a polarization technique, with a single mode from a second similarly frequency-stabilized HeNe laser. Wavelength instability of a commercially packaged $1.52 \mu \mathrm{m}$ distributedfeedback diode laser is in the range $\pm 1 \mathrm{ppm}$.
\end{abstract}

Key words: single mode; diode laser; wavelength measurement; wavelength instability; optical fiber communications; lambdameter.

\title{
1. Introduction
}

The purpose of this research is to build a precision lambdameter for use as a standard for measuring the wavelength of infrared radiation from single-mode diode laser sources used in optical fiber communication systems. The sources of interest are primarily distributed-feedback (DFB) laser diodes emitting at 1.3 and $1.5 \mu \mathrm{m}$, but distributed Bragg reflector (DBR) laser diodes are becoming increasingly important as well. Signal transmission at these wavelengths is desirable because certain classes of fibers exhibit minimum signal attenuation and dispersion at them. The zero dispersion wavelength of dispersion unshifted single-mode fibers (EIA class IV a) is $1.3 \mu \mathrm{m}$. Also, dispersion can be made vanishingly small for optical transmission at $1.55 \mu \mathrm{m}$ by suitable choice of refractive index profile and core radius in single-mode dispersion shifted fibers (EIA class IV b) in which signal attenuation is $<0.2 \mathrm{~dB} / \mathrm{km}$.

Our requirement is to measure wavelength within an uncertainty approximately equal to source linewidth. This can be achieved using a practical length of carriage motion and a technique that allows counting zero crossings of the fringe signal frequencies. Thus it is unnecessary to use one of the more complex fringe fraction counting methods to 
approach the desired accuracy [1-4]. A simple calculation gives the wavelength uncertainty for a $50 \mathrm{MHz}$ linewidth. If $\mathrm{c}$ is the speed of light in vacuum, $\nu$ the frequency, and $\lambda$ the vacuum wavelength of the source, then $\nu \lambda=c$, and

$$
\Delta \lambda=-\frac{\lambda^{2} \Delta \nu}{c} .
$$

For wavelength measurements at $1.52 \mu \mathrm{m}$ in vacuum or air, the condition on spatial linewidth becomes $\Delta \lambda \approx 4 \cdot 10^{-7} \mu \mathrm{m}$. The corresponding uncertainty in wavelength, $\Delta \lambda / \lambda$, is

$$
\frac{\Delta \lambda}{\lambda}=-\frac{\lambda \Delta \nu}{\mathrm{c}} \approx 0.25 \mathrm{ppm},
$$

so with a linewidth of $50 \mathrm{MHz}$ an accuracy $\mathrm{A} \approx 0.25 \mathrm{ppm}$ is acceptable. Our instrument's resolution is 0.1 to $0.2 \mathrm{ppm}$ and corresponds to $20 \mathrm{MHz}$. Resolution, which depends on the number of fringes counted, is limited by the linewidth-dependent phase uncertainty between the interfering beams. This phase uncertainty can be expressed as the ratio of a fringe fraction to the total number of fringes counted. It sets limits on the fraction of a fringe that can be counted and the accuracy to be gained by increasing the path difference.

The accuracy and resolution of lambdameters reported in the literature varies over many orders of magnitude, from about $1: 10^{6}$ to $1: 10^{11}$. These are given in the background section for general information, although a reported value may disagree with what the reader believes attainable for that particular system. Since it is not our purpose to study the limiting boundary conditions on accuracy, arguments on the validity of a reported accuracy are omitted. In section 5.6 the accuracy of our system is presented.

\section{Background}

The invention of the lambdameter, which is a scanning Michelson interferometer, arose from the need to rapidly measure the wavelength of single-mode, continuous-wave (cw) dye lasers with sub-Doppler accuracy. It was first developed by Hall and Lee [1], and Kowalski [5]. In each of these systems an original, independent optical design was employed. Hall and Lee [1,6] measured laser transitions in neon with an accuracy of $2: 10^{7}$. The system had a scan distance of $1.22 \mathrm{~m}$ and a uniquely folded path. Interference fringes in the optical signal were divided into 100 levels, and the corresponding output of an oscillator with this multiplied frequency was phase-locked with the optical fringe rate. This increased accuracy by a factor of 100 beyond that possible for simple fringe counting.

Kowalski's original optical design [5] required fewer critical optical components, but did not have a folded path. Fringe fractions were counted by two successive squaring circuits which quadrupled the count rate. Measurements were made on hyperfine components of iodine in the 510 to $570 \mathrm{~nm}$ range using a scan distance of $1 \mathrm{~m}$. A dye laser tuned 
to coincidence with several lines of atomic sodium confirmed accuracy to $6: 10^{8}$. This work includes an analysis of the variation of refractive index of air with wavelength and thermodynamic properties. An improved system with a novel folded-optical path and phase-locked loop to multiply fringe counting rate was later developed by Kowalski [7]. Accuracy was tested by measurements on the iodine $514.5 \mathrm{~nm}$ line and reported to be $1: 10^{8}$.

For wavelength measurements in the visible spectrum, Branberg and Nylen [8] developed a system with accuracy of about $1: 10^{6}$. To reduce the influence of drift and intensity fluctuations, the interference fringe signal was digitized by a comparator and the instantaneous value compared with its mean value. The correction due to the dispersion of air was eliminated by operating the system in a vacuum of $1 \mathrm{mPa}$.

Bennett and Gill [2] reported an uncertainty of $2: 10^{8}$ for wavelength measurements of several visible HeNe, $\mathrm{Ar}$ and $\mathrm{Kr}$ laser lines. To increase system accuracy, they developed a technique for counting fractional parts of an interference fringe at the beginning and end of a measurement. The dispersion correction was calculated from a new and simpler form, giving a result differing from the Edlen form [9] by only $1.5 \cdot 10^{8}$. The uncertainty due to dispersion was given as $5: 10^{8}$.

For wavelength measurements in the visible and infrared, Monchalin et al. [10] developed a vacuum-operated system. In the $10 \mu \mathrm{m}$ region, accuracy was limited by diffraction and reported to be several parts in $10^{9}$. In the visible range, accuracy was reported to be several parts in $10^{11}$. Data were analyzed by a technique in which the unknown wavelength was sampled for each zero crossing of the reference fringes. Groups of 1000 reference laser fringes were sampled, and the relative phase of the corresponding unknown laser fringes calculated by a Fourier summation scheme. The standard deviation was given as 0.003 of a reference $\mathrm{HeNe}$ fringe. The reference laser was an iodine Lamb-dip-stabilized HeNe calibrated with respect to a basic $\mathrm{Kr}$ length standard.

Bonsch [11] developed a lambdameter to measure the wavelength ratio of methane-stabilized $\mathrm{HeNe}$ at $3.39 \mu \mathrm{m}$ to iodine-stabilized HeNe at $0.633 \mu \mathrm{m}$. The reported uncertainty was $3: 10^{10}$, with diffraction the limiting factor. By vibrating the interferometer's reference mirror and analyzing the fringe signals by phase-sensitive detection, the reported uncertainty in the determination of fractional interference orders was $10^{-4}$. A modification of this interferometer using a single polarization fiber for coupling light to the interferometer was reported to render insignificant the error due to optical beam misalignment [12]. With this modification, a relative uncertainty of $4: 10^{11}$ (which was smaller than the reproducibilities of the lasers) was reported by simultaneously comparing iodine-stabilized laser lines at $515 \mathrm{~nm}, 633 \mathrm{~nm}$, and $640 \mathrm{~nm}$.

The wavelengths of two HeNe lasers differing by only $1: 10^{7}$ were compared by a system employing a vernier fringe-counting circuit. This method required coincidence in the phases of the two detected waveform signals at both the beginning and end of the counting cycle. Using this 
system, Kahane et al. [13] report a reproducibility of $5: 10^{9}$ and an accuracy of $4: 10^{9}$. The vernierlike coincidence concept is also described in a wavemeter using a compact spherical interferometer [14].

Kowalski et al. [3] later developed a system which corrected for interference fringe dropouts caused by transient dye laser instabilities. Missing fringes were accounted for by comparing numbers counted in an interval with a preceding reference interval. Fractional fringes were monitored by measuring the time separation between the first observed dye-laser fringe and the first HeNe reference-laser fringe. This was done with a signal 100 times faster than the fringe signal rate and the procedure repeated at the end of a scan. The setup was placed in a vacuum chamber and the uncertainty due to dispersion was reported to be $1: 10^{10}$ with instrument precision on the order of $1: 10^{8}$.

A vacuum-operated system with a new optical design was more recently developed by Ishikawa et al. [4,15]. It had a multiple folded-path and specially built rigid structure for improved accuracy. Multicoincidence fringe counting logic was used to determine coincidence points for the fringe signals from the reference and unknown lasers. With this technique fringe fractions were reportedly resolved to $1 / 500$ of a fringe. The wavelength ratio of stabilized HeNe lasers at $612 \mathrm{~nm}$ and $633 \mathrm{~nm}$ was measured with an uncertainty $<4: 10^{10}$.

Junttila et al. [16] developed a Fourier transform lambdameter for multimode diode laser measurements and single-mode, long-term frequency stability measurements. A two-mode, polarization-stabilized, $543 \mathrm{~nm}$ HeNe laser was compared with an iodine-stabilized, $633 \mathrm{~nm}$ HeNe laser with an uncertainty $<1: 10^{7}$. Multimode diode laser spectra at $840 \mathrm{~nm}$ and $1300 \mathrm{~nm}$ were also investigated. To eliminate errors due to misalignment between the reference and unknown laser beams, the light was fiber-optically coupled into the interferometer. Shifting and broadening of peaks was observed for diode-laser environmental temperature changes on the order of $0.1 \mathrm{~K}$.

A high-accuracy lambdameter was reported by Cachenaut et al. [17]. The wavelength of a $612 \mathrm{~nm}$ HeNe laser stabilized to a saturated absorption peak of iodine was measured with an accuracy of $1.6: 10^{9}$. Fringes from the unknown and reference lasers were simultaneously counted, then compared at a phase detector with the output of a voltage controlled oscillator (VCO). The VCO frequency was multiplied by a factor of 128 and phase locked by feedback from the output of the phase comparator. A resolution of $1.4 \mathrm{fm}$ allowed for measurement of the iodine hyperfine structure with a precision of about $2.5 \mathrm{fm}$.

To study dye-laser wavelengths, Mulders et al. [18] developed a system employing a phase-locked loop by which the fringe frequency could be multiplied by a factor of 10 . Wavelength measurements were updated every second with an accuracy of $0.01 \mathrm{~nm}$. Missing fringes due to dyelaser beam interruptions that probably arose from air bubbles in the lasing area of the dye jet stream were investigated. 
In another system, Rowley et al. [19] reported an accuracy of $1: 10^{7}$, with the diffraction error estimated to be less than $1: 10^{8}$. Evans and Lambert [20] studied lead-salt diode laser wavelengths, reporting an accuracy of a few parts in $10^{6}$ with their system. Using Murty's modified Michelson design $[21,22]$, and with the scanning corner cube mounted on a toy electric train with foam rubber, Hui-Rong et al. [23] report an accuracy of $1: 10^{6}$. Finally, Milan et al. [24] developed a system with a reported precision between $1: 10^{8}$ and $1: 10^{9}$. For a review of laser wavelength meters see references 25 and 26 .

\section{Principle of Lambdameter}

The simplest scheme using a travelling wavemeter to measure the wavelength of a cw laser source is based on the Michelson interferometer. One portion of a split beam reflects from a scanning mirror through a fixed distance. The second portion reflects from a stationary mirror and the interference fringes from the recombining beams are counted at a detector. The most precise way of measuring the scan distance is to simultaneously count the fringes from a second laser of known wavelength over the same scan distance. In the lambdameter, instead of plane mirrors, corner cubes are preferred because they return a beam antiparallel to the direction of its incidence. If the return beam is precise within a few arcseconds, the interferometer is insensitive to misalignment, since the reference and unknown laser beams traverse nearly identical paths through the interferometer. Upon exiting the interferometer, each of the two wavelengths forms a distinct set of interference fringes that is focused onto a separate photodetector. The signals from each photodetector are simultaneously counted and the ratio of the two numbers taken. The number of fringes counted for each wavelength is proportional to the distance through which the corner cubes travel.

The common path associated with the scan gives rise to the relations

$$
\begin{aligned}
\mathrm{N}_{\mathrm{r}} \lambda_{\mathrm{r}} / \mathrm{n}_{\mathrm{r}} & =\mathrm{N}_{\mathrm{u}} \lambda_{\mathrm{u}} / \mathrm{n}_{\mathrm{u}} \\
\mathrm{N}_{\mathrm{r}} \lambda_{\mathrm{r}}\left(\mathrm{n}_{\mathrm{r}}\right) & =\mathrm{N}_{\mathrm{u}} \lambda_{\mathrm{u}}\left(\mathrm{n}_{\mathrm{u}}\right),
\end{aligned}
$$

where $r$ is reference and $u$ is unknown; $\lambda$ is vacuum wavelength; $\lambda(n)$ is dispersion dependent wavelength; $\mathrm{n}$ is the corresponding refractive index of the propagation medium; and $\mathrm{N}$ is number of fringes counted. If for the propagation medium, $\mathrm{T}=$ temperature, $\mathrm{P}=$ total pressure or sum of partial pressures, $h=$ partial pressure of water vapor, and $\mathrm{C}=$ fractional $\mathrm{CO}_{2}$ concentration, then

$$
\begin{aligned}
& \mathrm{n}_{\mathrm{r}}=\mathrm{n}_{\mathrm{r}}\left(\mathrm{T}, \mathrm{P}, \mathrm{h}, \mathrm{C}, \lambda_{\mathrm{r}}\right) \\
& \mathrm{n}_{\mathrm{u}}=\mathrm{n}_{\mathrm{u}}\left(\mathrm{T}, \mathrm{P}, \mathrm{h}, \mathrm{C}, \lambda_{\mathrm{u}}\right) .
\end{aligned}
$$


This allows us to solve for the unknown wavelength given suitable knowledge of the refractive indices.

Since $\mathrm{n}_{\mathrm{u}}$ depends on $\lambda_{\mathrm{u}}$ which is unknown, we solve eq (1) for $\lambda_{\mathrm{u}}\left(\mathrm{n}_{\mathrm{u}}\right)$. Now for normal atmospheric conditions

$$
\mathrm{n}_{\mathrm{u}}\left(\mathrm{T}, \mathrm{P}, \mathrm{h}, \mathrm{C}, \lambda_{\mathrm{u}}\right)-\mathrm{n}_{\mathrm{u}}\left(\mathrm{T}, \mathrm{P}, \mathrm{h}, \mathrm{C}, \lambda_{\mathrm{u}}\left(\mathrm{n}_{\mathrm{u}}\right)\right)<10^{-8}
$$

as will be shown in section 4.2 on dispersion. Substituting $\mathrm{n}_{\mathrm{u}}\left(\mathrm{T}, \mathrm{P}, \mathrm{h}, \mathrm{C}, \lambda_{\mathrm{u}}\left(\mathrm{n}_{\mathrm{u}}\right)\right)$ for $\mathrm{n}_{\mathrm{u}}\left(\mathrm{T}, \mathrm{P}, \mathrm{h}, \mathrm{C}, \lambda_{\mathrm{u}}\right)$ we arrive at the vacuum wavelength as a function of measurable quantities,

$$
\begin{gathered}
\lambda_{\mathrm{u}}\left(\mathrm{n}_{\mathrm{u}}\right)=\lambda_{\mathrm{u}} / \mathrm{n}_{\mathrm{u}}=\lambda_{\mathrm{u}} / \mathrm{n}_{\mathrm{u}}\left(\mathrm{T}, \mathrm{P}, \mathrm{h}, \mathrm{C}, \lambda_{\mathrm{u}}\right) \\
\lambda_{\mathrm{u}} \approx \lambda_{\mathrm{u}}\left(\mathrm{n}_{\mathrm{u}}\right) \cdot \mathrm{n}_{\mathrm{u}}\left(\mathrm{T}, \mathrm{P}, \mathrm{h}, \mathrm{C}, \lambda_{\mathrm{u}}\left(\mathrm{n}_{\mathrm{u}}\right)\right) .
\end{gathered}
$$

Thus determination of the vacuum wavelength of the unknown laser for accuracies higher than $0.1 \mathrm{ppm}$ requires that we operate the system in vacuum or have knowledge of the refractive index. For accuracies of $0.1 \mathrm{ppm}$ careful attention must be given to fluctuations in atmospheric parameters, especially temperature and pressure. The dispersion is considered in more detail in section 4.2 .

\section{Accuracy and Resolution}

The accuracy of a lambdameter is a measure of its ability to yield the true wavelength of a single-mode laser source of linewidth narrow enough not to limit the measurement at that wavelength. If a lambdameter measures wavelength within one part in $10^{\mathrm{k}}$ (where $\mathrm{k}$ is an integer), it has an accuracy of $1: 10^{\mathrm{k}}$ in our notation. Thus the higher the accuracy, the smaller the number representing it. The resolution, $\Delta \lambda / \lambda$, is limited by the counting error and is described in section 4.1 below. A frequency-stabilized reference laser with known wavelength and a stability greater than the desired resolution is needed.

Effects that reduce accuracy in a lambdameter can be divided into wavelength-dependent and nearly wavelength-independent contributions. All of these can be rendered insignificant for accuracies of the order of $0.1 \mathrm{ppm}$. The wavelength-dependent contributions are dispersion and diffraction. The nearly wavelength-independent contributions are the angular misalignment between the reference and unknown beams, and the dependence of the refractive indices on atmospheric parameters such as pressure, temperature, humidity, and $\mathrm{CO}_{2}$ content. The remaining aberrations of the wavefronts and diffraction, although wavelength dependent, are insignificant, even when we use inexpensive optics.

\subsection{Path Folding}

Taking the differential of eq (1) shows that resolution increases inversely with the number of fringes counted during a scan of the 
carriage. (This is done by using the result $\delta\left(n_{u} / n_{r}\right) \approx 0$, derived in section 4.2 on dispersion.) Path folding results in higher fringe counts, hence greater resolution. The accuracy can be made equal to the resolution by eliminating all other sources of error. If $p$ is the degree of path folding, $z$ the fraction of a fringe counted, and $\Delta x$ the scan distance of a corner cube, then the resolution is

$$
\mathrm{R}_{\mathrm{e}}=\Delta \lambda / \lambda=\frac{\lambda}{\mathrm{zp} \Delta \mathrm{x}}
$$

where $\lambda$ is the wavelength of the reference or unknown laser [17], depending on which laser is used to trigger the counter. In our present version $\mathrm{p}=4, \lambda=1.52 \mu \mathrm{m}, \Delta \mathrm{x} \approx 1.22 \mathrm{~m}$, and $\mathrm{z}=2$ (zero crossings are counted), so $R \approx 1.5 \cdot 10^{-7}$. Some folded-path designs appearing in the literature are shown in appendix $B$.

Extensive path folding has limitations due to phase uncertainty (as discussed in section 4.6) and can present other problems as well. Vibrations of the moving carriage with corner cubes induce a jitter of the optical signal at the distant photodetectors of magnitude directly proportional to the effective scan length. For long distances, fluctuating power levels may induce false counts. Optical power loss and wavefront distortion increase due to the additional optical components needed to fold the paths.

\subsection{Dispersion of Air}

The dispersion of air can be calculated and its effect on accuracy can be estimated. Many approximations for the refractive index are scattered throughout the literature [9,27-31]. A useful result for standard dry air is given by Edlen [9] (he takes $\mathrm{T}=15^{\circ} \mathrm{C}, \mathrm{P}=101325 \mathrm{~Pa}$ (760 Torr)),

$$
\left(n_{s}-1\right) \cdot 10^{8}=8342.13+\frac{2406030}{130-1 / \lambda^{2}}+\frac{15997}{38.9-1 / \lambda^{2}}
$$

where $n_{s}$ is the refractive index and $\lambda$ is the vacuum wavelength in micrometers. Addition of temperature and atmospheric pressure dependence yields

$$
\mathrm{n}(\mathrm{T}, \mathrm{P})-1=\frac{\left(\mathrm{n}_{\mathrm{s}}-1\right)(0.00138823)(133.31556 \mathrm{P})}{1+0.003671 \mathrm{~T}}
$$

where $T$ is in degrees Celsius, $P$ is in pascals, and 133.31556 pascals $=1$ torr. Finally, for visible radiation propagating through moist air, a correction for water vapor gives

$$
\mathrm{n}(\mathrm{T}, \mathrm{P}, \mathrm{h})=\mathrm{n}(\mathrm{T}, \mathrm{P})-133.31556 \cdot \mathrm{h} \cdot\left(5.722-0.0457 / \lambda^{2}\right) 10^{-8},
$$

where $h$ is the partial pressure of water vapor in pascals. 
For infrared wavelengths $>1 \mu \mathrm{m}$, a modified form for the dispersion [9] is given as

$$
\left(n_{s}-1\right) \cdot 10^{8}=\left(27261.1+154.3 / \lambda^{2}\right) .
$$

Since the refractive index as calculated above depends on the vacuum wavelength, and a lambdameter operating in air measures the dispersion dependent wavelength, we justify an approximation which converts from one to the other. We show that in the refractive index for the unknown wavelength, the vacuum wavelength can be replaced by the wavelength in the medium, $\lambda(n)$. Thus

$$
\begin{gathered}
\mathrm{n}=\mathrm{n}(\mathrm{T}, \mathrm{P}, \mathrm{h}, \mathrm{C}, \lambda) \\
\lambda=\lambda(\mathrm{n}) \cdot \mathrm{n}(\mathrm{T}, \mathrm{P}, \mathrm{h}, \mathrm{C}, \lambda) .
\end{gathered}
$$

Using eq (6) above and $\lambda_{\mathrm{r} 1}=0.632991287 \mu \mathrm{m}$ for the vacuum wavelength of our reference HeNe, we find $n_{r_{1}} \approx 1.00027652$. Thus the dispersiondependent wavelength is $\lambda_{r_{1}}\left(n_{r_{1}}\right)=\lambda_{r_{1}} / n_{r_{1}} \approx 0.63281630 \mu m$. Substituting into eq (6), we find $\mathrm{n}^{\prime}{ }_{\mathrm{r} 1}=1.00027652$. Finally,

$$
n^{\prime}{ }_{1}-n_{r 1}<10^{-8} \text {. }
$$

The temperature and pressure dependence is found from eq (7). At $\mathrm{T}=23^{\circ} \mathrm{C}$ and $\mathrm{P}=0.82922 .28 \cdot 10^{5} \mathrm{~Pa}(622$ Torr $)$, we have $\mathrm{n}^{\prime}(\mathrm{T}, \mathrm{P})-\mathrm{n}(\mathrm{T}, \mathrm{P})$ $\approx 0.8 \cdot\left(n^{\prime}{ }_{r 1}-n_{r 1}\right)<10^{-8}$.

As an example for the IR region, we use eq (9) and an assumed value $\lambda_{\mathrm{u}}=1.520 \mu \mathrm{m}$ to calculate $\mathrm{n}_{\mathrm{u}} \approx 1.00027328$. The dispersion-dependent wavelength is then $\lambda_{u}\left(n_{u}\right)=\lambda_{u} / n_{u} \approx 1.51958473 \mu \mathrm{m}$. Substituting this value into eq $(8)$ gives $n^{\prime}{ }_{u} \approx 1.00027328$. Finally,

$$
\mathrm{n}^{\prime}{ }_{\mathrm{u}}-\mathrm{n}_{\mathrm{u}}<10^{-8}
$$

Therefore we generalize to the relation,

$$
\lambda_{\mathrm{u}} \approx \lambda\left(\mathrm{n}_{\mathrm{u}}\right) \cdot \mathrm{n}_{\mathrm{u}}\left(\mathrm{T}, \mathrm{P}, \mathrm{h}, \mathrm{C}, \lambda\left(\mathrm{n}_{\mathrm{u}}\right)\right),
$$

which allows us to find the vacuum wavelength of the unknown source for accuracies on the order of $0.1 \mathrm{ppm}$. Precise knowledge of the refractive index of air through optical interferometric displacement measurements can be no greater than $\pm 8.5: 10^{8}$ [27].

Partial differentiation of eqs (7) and (8) gives the change in temperature, pressure, and humidity required to alter the refractive index by $0.1 \mathrm{ppm}$ and $0.01 \mathrm{ppm}$. The results are shown in table 1 [27], but with humidity converted to percent. See reference 27 for the $\mathrm{CO}_{2}$ dependence. 
Table 1. Change in a thermodynamic variable required to alter the refractive index by 0.1 and $0.01 \mathrm{ppm}$.

\begin{tabular}{lccc}
\hline & Initial value & $\Delta \mathrm{n} \approx 10^{-8}$ & $\Delta \mathrm{n} \approx 10^{-7}$ \\
\hline Pressure $(\mathrm{Pa})$ & $1.013 \cdot 10^{5}(760$ Torr $)$ & $4(0.03$ Torr $)$ & $40(0.3$ Torr $)$ \\
Temperature $\left({ }^{\circ} \mathrm{C}\right)$ & 20 & -0.01 & -0.131 \\
Humidity $(8)$ & 40 & -1 & -10 \\
$\mathrm{CO}_{2}(\mathrm{ppm})$ & 340 & 67 & - \\
\hline
\end{tabular}

Of greatest importance, however, is the thermodynamic influence on the ratio of the refractive indices of the reference and unknown lasers instead of each index separately. We now show that the variation of this ratio is independent of normal fluctuations in temperature, pressure, and humidity, and that we need only specify an arbitrary refractive index corresponding to the reference wavelength. The variation of the ratio of the fringe counts, $R$, due to thermodynamic considerations is

$$
\delta R \approx \text { const } \cdot \delta\left[n_{u}(T, P) / n_{r}(T, P)\right] .
$$

We rewrite eq (7) as

$$
n(T, P)-1=\frac{\left(n_{s}-1\right) a P}{1+b T}
$$

where $a=0.00138823$, and $b=0.003671$. Then

$$
\begin{aligned}
& \mathrm{n}_{\mathrm{u}}(\mathrm{T}, \mathrm{P})=1+\frac{\mathrm{aP}\left(\mathrm{n}_{\mathrm{s}}\left(\lambda_{\mathrm{u}}\right)-1\right)}{1+\mathrm{bT}}, \\
& \mathrm{n}_{\mathrm{r}}(\mathrm{T}, \mathrm{P})=1+\frac{\mathrm{aP}\left(\mathrm{n}_{\mathrm{s}}\left(\lambda_{\mathrm{r}}\right)-1\right)}{1+\mathrm{bT}},
\end{aligned}
$$

so

$$
\frac{n_{u}(T, P)}{n_{r}(T, P)} \equiv L=\frac{1+b T+k_{u} P}{1+b T+k_{r} P}
$$

where $\mathrm{k}_{\mathrm{u}}=\mathrm{a}\left(\mathrm{n}_{\mathrm{s}}\left(\lambda_{\mathrm{u}}\right)-1\right)$, and $\mathrm{k}_{\mathrm{r}}=\mathrm{a}\left(\mathrm{n}_{\mathrm{s}}\left(\lambda_{\mathrm{r}}\right)-1\right)$. The variation in $\mathrm{L}$ is then

$$
\delta \mathrm{L} \approx \frac{\partial \mathrm{L}}{\partial \mathrm{P}} \delta \mathrm{P}+\frac{\partial \mathrm{L}}{\partial \mathrm{T}} \delta \mathrm{T}
$$

so for $\lambda_{\mathrm{u}}=1.52 \mu \mathrm{m}, \lambda_{\mathrm{r}}=0.632 \mu \mathrm{m}$, we have 


$$
\frac{\partial \mathrm{L}}{\partial \mathrm{P}} \approx \mathrm{k}_{\mathrm{u}}-\mathrm{k}_{\mathrm{r}} \approx \mathrm{a}\left(\mathrm{n}_{\mathrm{s}}\left(\lambda_{\mathrm{u}}\right)-\mathrm{n}_{\mathrm{s}}\left(\lambda_{\mathrm{r}}\right)\right) \approx 5 \cdot 10^{-9}
$$

where the denominator has been omitted since it is very close to 1 . Also,

$$
\frac{\partial \mathrm{L}}{\partial \mathrm{T}} \approx \mathrm{bP}\left(\mathrm{k}_{\mathrm{u}}-\mathrm{k}_{\mathrm{r}}\right) \approx 10^{-8}
$$

The dependence of $\mathrm{L}$ on $\mathrm{h}$ is even smaller. From eq (8) with $\mathrm{L}$ defined by the ratio of humidity-dependent indices, we have

$$
\frac{\partial \mathrm{L}}{\partial \mathrm{h}} \approx\left(5.61 \mathrm{n}_{\mathrm{u}}(\mathrm{T}, \mathrm{P})-5.7 \mathrm{n}_{\mathrm{r}}(\mathrm{T}, \mathrm{P})\right) \cdot 10^{-8}
$$

We evaluate this term at $\mathrm{T}=23^{\circ} \mathrm{C}, \quad \mathrm{P}=82922.23 \mathrm{~Pa}$ (622 Torr). The result is $\approx 10^{-9}$. Thus a 50 percent change in humidity, corresponding to $\approx 1466.5 \mathrm{~Pa}$ (11 Torr) changes $\mathrm{L}$ by only $\approx 1: 10^{8}$ and eliminates humidity as a potential source of error. Therefore L, and therefore $R$, easily remains constant within $1: 10^{7}$ for pressure changes $\leq 2666.3 \mathrm{~Pa}$ (20 Torr) or temperature changes $\leq 10^{\circ} \mathrm{C}$. We can specify the unknown wavelength in the medium as a function of $T, P$, and the refractive index of the reference laser. Thus

$$
\lambda_{u}\left(n_{u}\right)=\frac{\lambda_{r}(1+b T)}{R\left(1+b T+a P\left(n_{s}\left(\lambda_{r}\right)-1\right)\right)} .
$$

In our system, the time for a set of measurements takes $\leq 1 \mathrm{~h}$, so that dependence of $L$ on these variables does not contribute to loss in accuracy.

At the NIST Boulder laboratories, average atmospheric pressure is about $829222.23 \mathrm{~Pa}$ (622 Torr) with diurnal cycles of 200 to $300 \mathrm{~Pa}$ (a few Torr) caused by atmospheric tides. This can fluctuate by as much as 2000 $\mathrm{Pa}$ (15 Torr) a week due to normal high and low pressure weather systems, and 2666 to $4000 \mathrm{~Pa}$ (20 to 30 Torr) over a season. The fluctuations are greatest in winter and spring [32]. The pressure gradient at the earth's surface due to gravitation $(-13.33 \mathrm{~Pa} / \mathrm{m}(-0.1$ Torr $/ \mathrm{m}))$ changes the refractive index by $\approx 3$ parts in $10^{8}$ per meter of vertical translation. Also, convection can cause significant horizontal as well as vertical thermal gradients. Horizontal gradients have been observed as great as several tenths of a kelvin over distances as small as $1 \mathrm{~m}$ [27].

\subsection{Diffraction}

Diffraction is an error source that must be considered because of the finite waist size of the laser beams. Given a fixed plane outside the interferometer such as the surface of a photodetector, two beams recombining at this plane will have traversed different distances. This difference is directly proportional to the displacement of the scanning components from the equal path position. Thus the wavefronts of the two 
beams will have different curvatures; the difference is greatest at the endpoints and least at the center of motion. In comparison to the time dependence of the well-behaved phase of the interference fringe signal from two plane waves, the phase of interfering wavefronts of slightly different and changing curvature will vary.

If we ignore wavefront aberrations due to imperfections in the interferometer, a first-order diffraction correction to the wavelength $[11,12]$ is

$$
\frac{\Delta \lambda}{\lambda}=\frac{\lambda^{2}}{\left(2 \pi w_{0}\right)^{2}}
$$

where $w_{0}$ is the waist size of the beam. For beams with $w_{0} \approx 5 \mathrm{~mm}$ such as those used in our system, the diffraction correction is $\approx 4: 10^{10}$ at the HeNe reference wavelength of $0.632 \mu \mathrm{m}, \approx 1.7: 10^{9}$ at $1.3 \mu \mathrm{m}$, and $\approx 2.2: 10^{9}$ at $1.5 \mu \mathrm{m}$. Since our accuracy is $\approx 1: 10^{7}$, we can neglect diffraction.

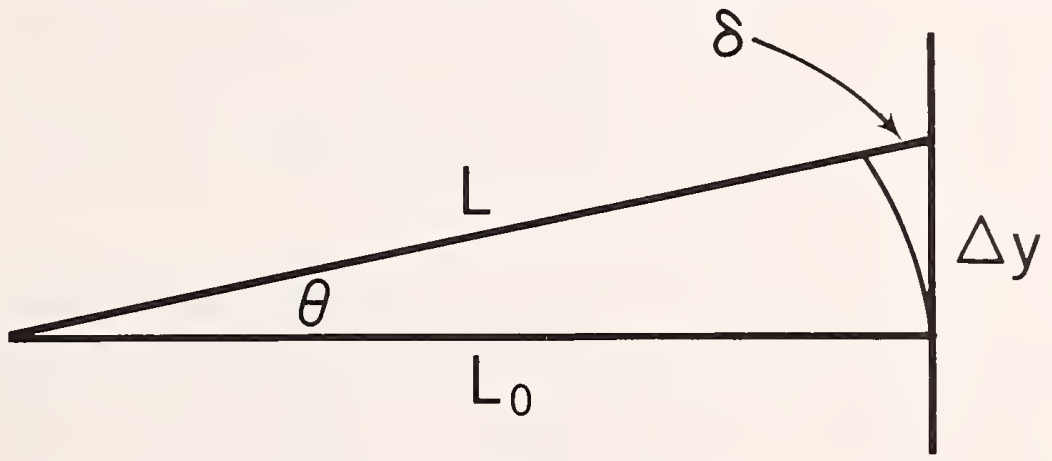

Figure 1. Angular misalignment of the reference and unknown lasers. $\mathrm{L}_{\circ}$ is the equivalent path travelled by the reference laser over the carriage motion. A hypothetical detector surface is arbitrarily aligned perpendicular to $L_{0}$. L is the equivalent path of the unknown beam over the carriage motion, shown misaligned by an angle $\theta . \Delta y$ is the linear misalignment of the beams at the surface and $\delta$ is the extra distance travelled by the misaligned beam.

\subsection{Colinearity of the Reference and Unknown Laser Beams}

Consider a misalignment of the reference and unknown laser beams [5] as shown in figure 1 . Let $\mathrm{L}_{0}$ be the distance traversed by the reference beam; the beam is incident perpendicular to the detector surface. Let $L$ be the distance traversed by the unknown beam which is incident upon the detector surface at an angle $\theta$. Then, if $\Delta y$ is the linear misalignment of the beams at the surface, we have

$$
\begin{gathered}
\mathrm{L}=\mathrm{L}_{0}+\delta \\
\mathrm{L}_{0}=\mathrm{L} \cos \theta=\left(\mathrm{L}_{0}+\delta\right) \cos \theta
\end{gathered}
$$


where $\tan \theta=\Delta y / L$. Now $\tan \theta$ can be approximated by $\theta$ with the error occurring at $1: 10^{9}$, which is negligible for our requirements. Thus,

$$
\begin{aligned}
\delta & =L-L_{0}=L(1-\cos \theta) \\
& =L\left[1-\left(1-\theta^{2} / 2+\ldots\right)\right] \\
& \approx \frac{L}{2}\left[\frac{\Delta y}{L}\right]^{2} \\
& =\frac{1}{2 L}(\Delta y)^{2} .
\end{aligned}
$$

For our system, $\mathrm{L} \approx 4.7 \mathrm{~m}$ and $\Delta \mathrm{y} \leq 1.0 \mathrm{~mm}$. Substituting into eq (21) gives $\delta \leq 1.06 \times 10^{-7} \mathrm{~m}$. In table $2, \delta$ is expressed as a fraction of a fringe; $f \equiv \delta / \lambda$ for wavelengths relevant to our system. Misalignment reduces accuracy by an amount $f /(N+f) \approx f / N$, where $N$ is the number of fringes counted. Since $(\mathrm{N}+\mathrm{f}) \lambda=\mathrm{L}$, accuracy is reduced by $\delta / \mathrm{L}$ $\leq 0.02 \mathrm{ppm}$ for all $\lambda$. To increase system accuracy by employing a fringe fraction counting technique requires that the alignment be more accurate than the fraction of a fringe counted. Our system counts signal zerocrossings or half fringes, so that misalignment is insignificant. For applications requiring accuracy $A<1: 10^{7}$, small fringe fractions must be counted. Thus misalignment can limit accuracy.

of equal importance is angular misalignment between the two interfering beams from the same laser. However, if the reference and unknown beams are made colinear, this error is negligible. Furthermore, the symmetry of the optical design, figure 2, shows that if the beams are initially aligned for each wavelength, a misalignment arising from a displacement of the corner cubes perpendicular to their motion retains equal optical path lengths for the two wavelengths.

Table 2. Path misalignment (in fractions $f$ of a fringe) between reference and unknown beams for various wavelengths $\lambda$ using $\mathrm{L}=4.7 \mathrm{~m}$ and a misalignment of $1 \mathrm{~mm}$. The error due to misalignment is $\delta / L \leq 0.02 \mathrm{ppm}$ for all $\lambda$.

\begin{tabular}{lll}
\hline$\lambda(\mu \mathrm{m})$ & $\mathrm{f}$ & $\delta / \mathrm{L}(\mathrm{ppm})$ \\
\hline 0.63 & $1 / 6$ & 0.02 \\
1.00 & $1 / 10$ & 0.02 \\
1.3 & $1 / 12$ & 0.02 \\
1.5 & $1 / 14$ & 0.02
\end{tabular}




\subsection{Phase Uncertainty Between Recombining Beams}

The finite linewidth of the source results in a phase uncertainty between the recombining beams [7]. The present system is designed such that the ratio of the phase uncertainty to the total phase from the fringe counting over the scan distance is approximately equal to instrument resolution, $\delta \lambda / \lambda$, as we now show. Let $\Phi$ be the phase, $\Delta x$ the path difference, $N$ the number of fringes counted, $k$ the wavenumber, and $\Delta \nu$ the linewidth of the unknown source. Then $\Delta x=(N+\epsilon) \cdot \lambda$, where $\epsilon$ is the fraction of a fringe. For $N \gg \epsilon$ we drop $\epsilon$. Thus we have

$$
\begin{aligned}
\Phi & =\mathrm{k} \Delta \mathrm{x}=\frac{2 \pi \Delta \mathrm{x}}{\lambda}=\frac{2 \pi \nu \Delta \mathrm{x}}{\mathrm{c}}, \\
\delta \Phi & =\frac{2 \pi \Delta \mathrm{x} \delta \nu}{\mathrm{c}}, \\
\frac{\delta \Phi}{2 \pi} & =\frac{\Delta \mathrm{x} \delta \nu}{\mathrm{c}}, \\
\frac{\delta \Phi}{2 \pi \mathrm{N}} & =\frac{\Delta \mathrm{x} \delta \nu}{\mathrm{Nc}} \approx \frac{\lambda \delta \nu}{\mathrm{c}}=\frac{\delta \lambda}{\lambda} .
\end{aligned}
$$

For our system $\Delta \mathrm{x} \approx 4.88 \mathrm{~m}, \lambda \approx 1.52 \mu \mathrm{m}$, and $\mathrm{N} \approx 3.2 \cdot 10^{6}$ fringes. Now since the fringes are well defined over the entire scan, we estimate the linewidth to be $\leq 30 \mathrm{MHz}$. According to eq (22), the phase uncertainty is $\leq 0.488$ fringes. This limits the fraction of a fringe we may count to one-half at this linewidth. Equation (23) shows that the phase uncertainty over the entire scan is equal to the resolution defined by $\delta \lambda / \lambda$. Presently, we count zero crossings, or half fringes, and our resolution is $\approx 1.5 \cdot 10^{-7}$.

\subsection{Other Potential Sources of Error}

Additional potential sources of error are worth mentioning briefly. Because the carriage traverses a medium of open air, room turbulence can result in local fluctuations of the refractive indices. This effect is diminished by making the paths colinear, and retaining a constant optical path difference for the reference and unknown sources. Retroreflections from the various surfaces encountered by the beams can re-enter the lasers and cause destabilization. These are diminished by using optical isolators. A major source of retroreflections is the detector surface, and can be minimized by orienting its normal $\approx 40 \mathrm{deg}$ to the incident radiation [10]. Variations in the speed of the scanning retroreflectors causes fluctuations in fringe signal frequencies, resulting in a relative phase shift. This may result in an error due to the finite bandwidths of the detectors. Variations in speed of up to 5 percent, however, bring about negligible error [10]. 
5. System Design

5.1 Optical Design

In this design, the beam of the unknown wavelength is superimposed upon the reference beam using a dichroic beamsplitter/joiner, so that they are colinear as they traverse the interferometer. A displacement of the corner cubes by a distance $x$ yields a path difference of $4 \mathrm{x}$ between the interfering beams. A dichroic beamsplitter/joiner separates the two different wavelengths upon exiting. Each fringe signal is sent to its own detector for processing. Figure 2 is a sketch of the basic lambdameter design [1]. Figures $3 \mathrm{a}$ and $3 \mathrm{~b}$ show the path of a light ray through a corner cube. A ray exits the corner cube antiparallel to the direction of its incidence, but displaced an equal and opposite distance from the vertex. Figure 4 is a schematic of the optical components making up the system. Figure 5 is a photograph of the apparatus.

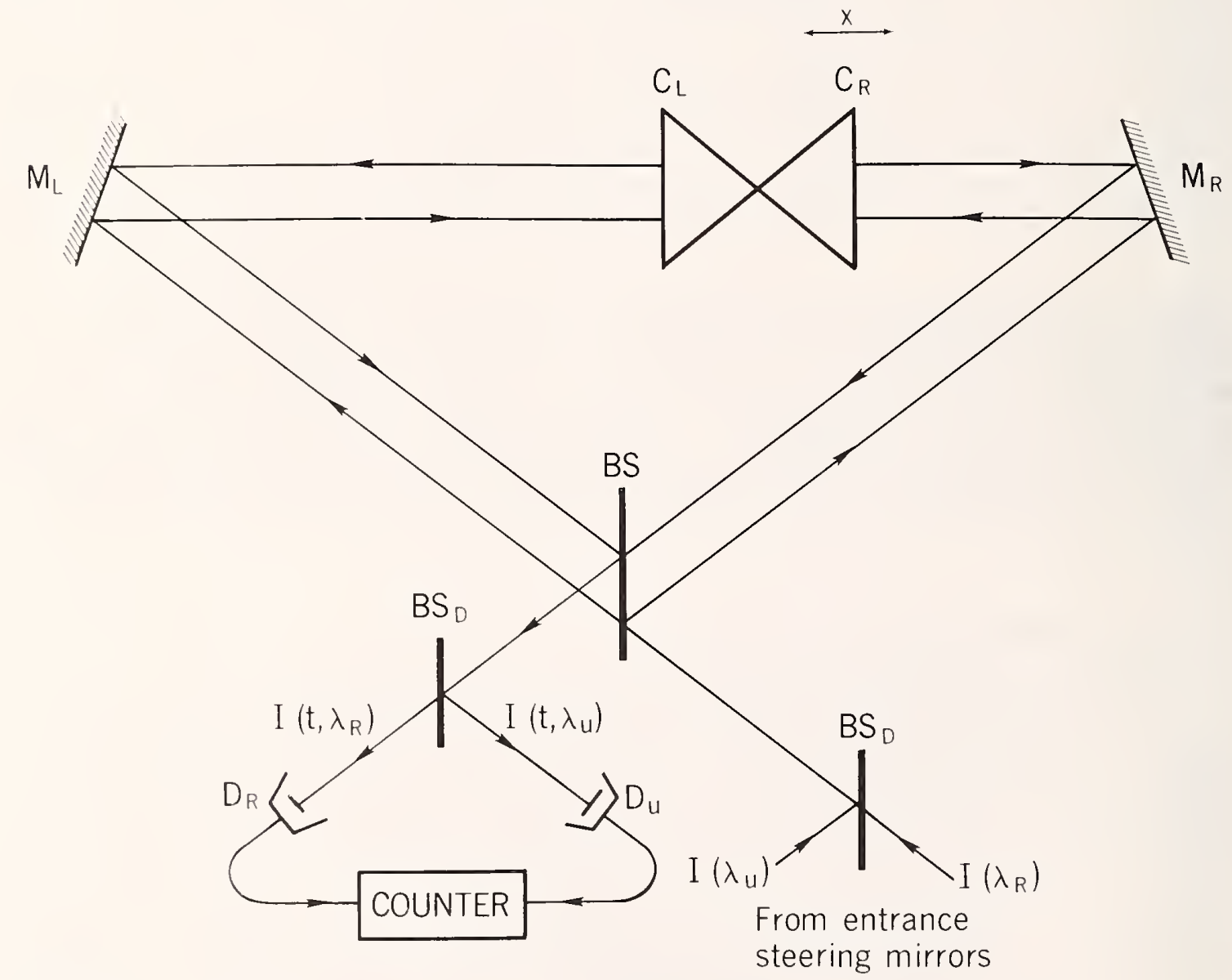

Figure 2. Optical design of the lambdameter [1]. $C_{L}, C_{R}$ are corner cubes, $M_{L}, M_{R}$ are steering mirrors, $B S$ is the Michelson beamsplitter, $B S_{D}$ is dichroic beamsplitter/joiners, and $D_{R}, D_{U}$ are photodetector devices. $I\left(\lambda_{U}\right)$ and $I\left(\lambda_{R}\right)$ represent the unknown and reference beams entering the interferometer. $I\left(t, \lambda_{U}\right)$ and $I\left(t, \lambda_{R}\right)$ represent the time-dependent fringe signals for the exiting unknown and reference beams. 


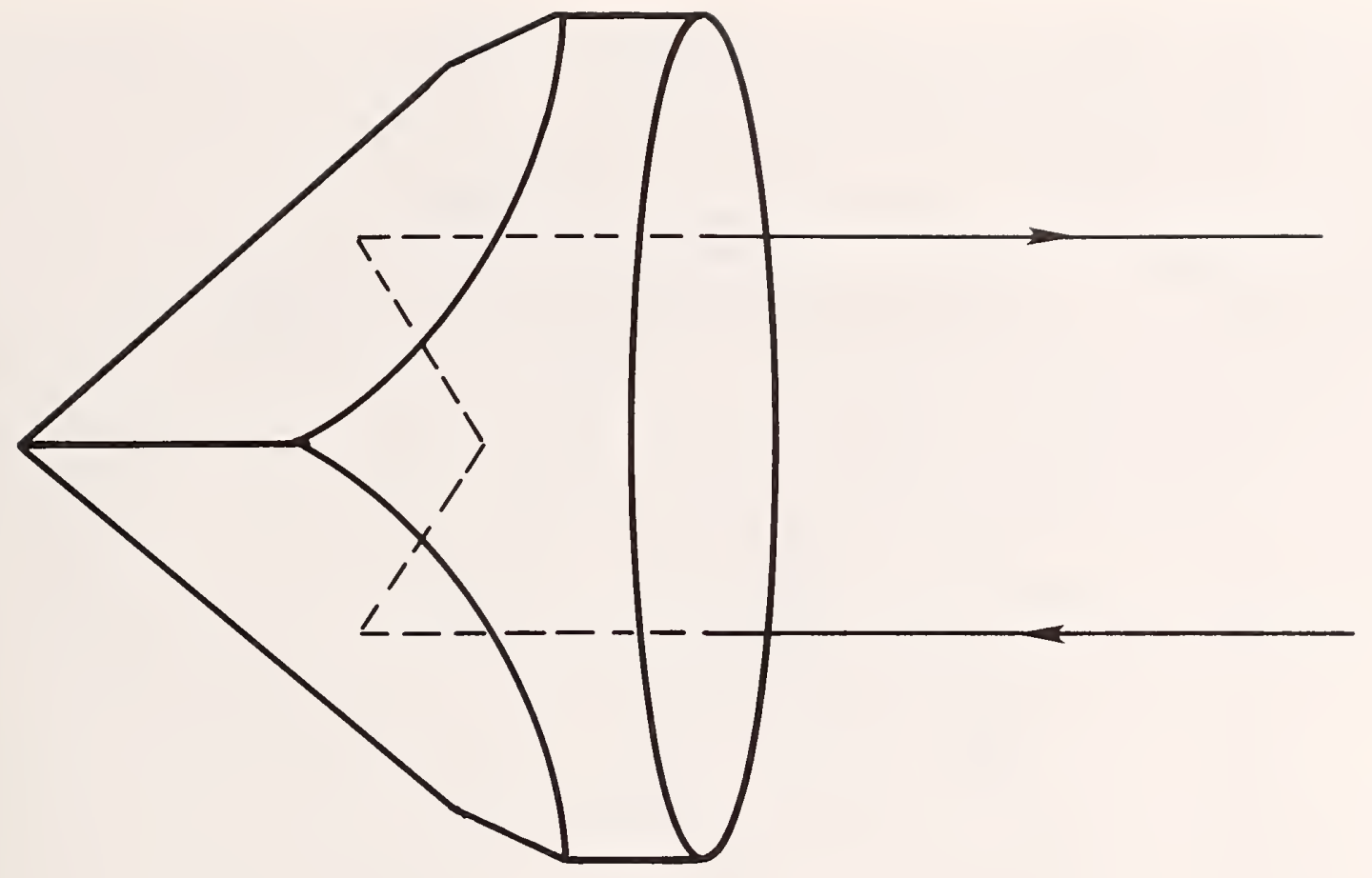

(a)

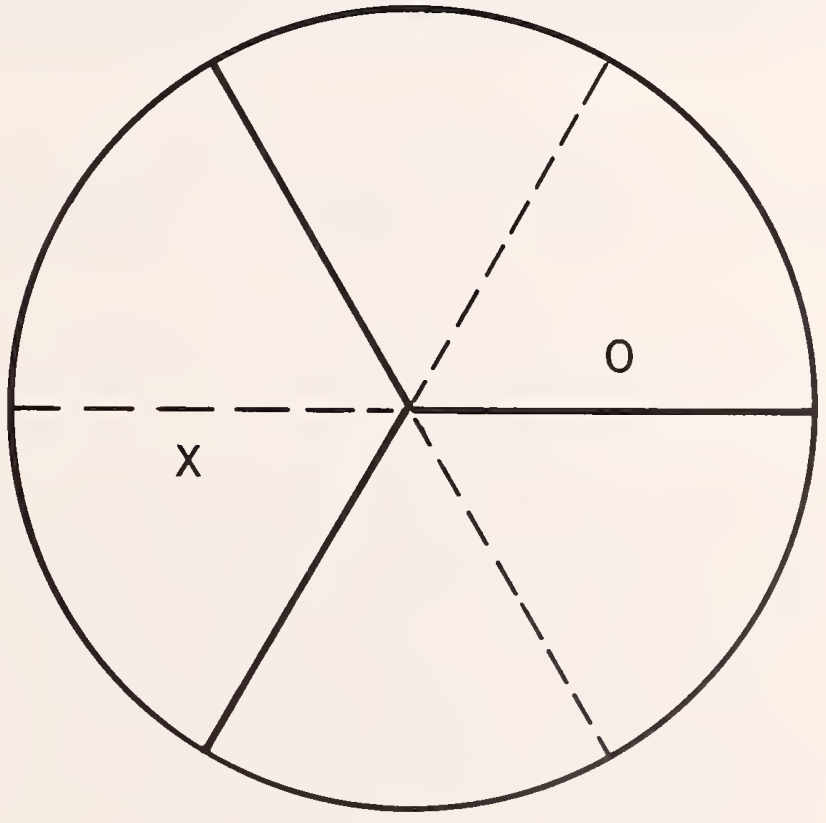

(b)

Figure 3. (a) Side view showing the path of a beam entering and exiting a corner cube. (b) Front view showing entrance and exit positions at points $\mathrm{x}$ and $\mathrm{o}$. 


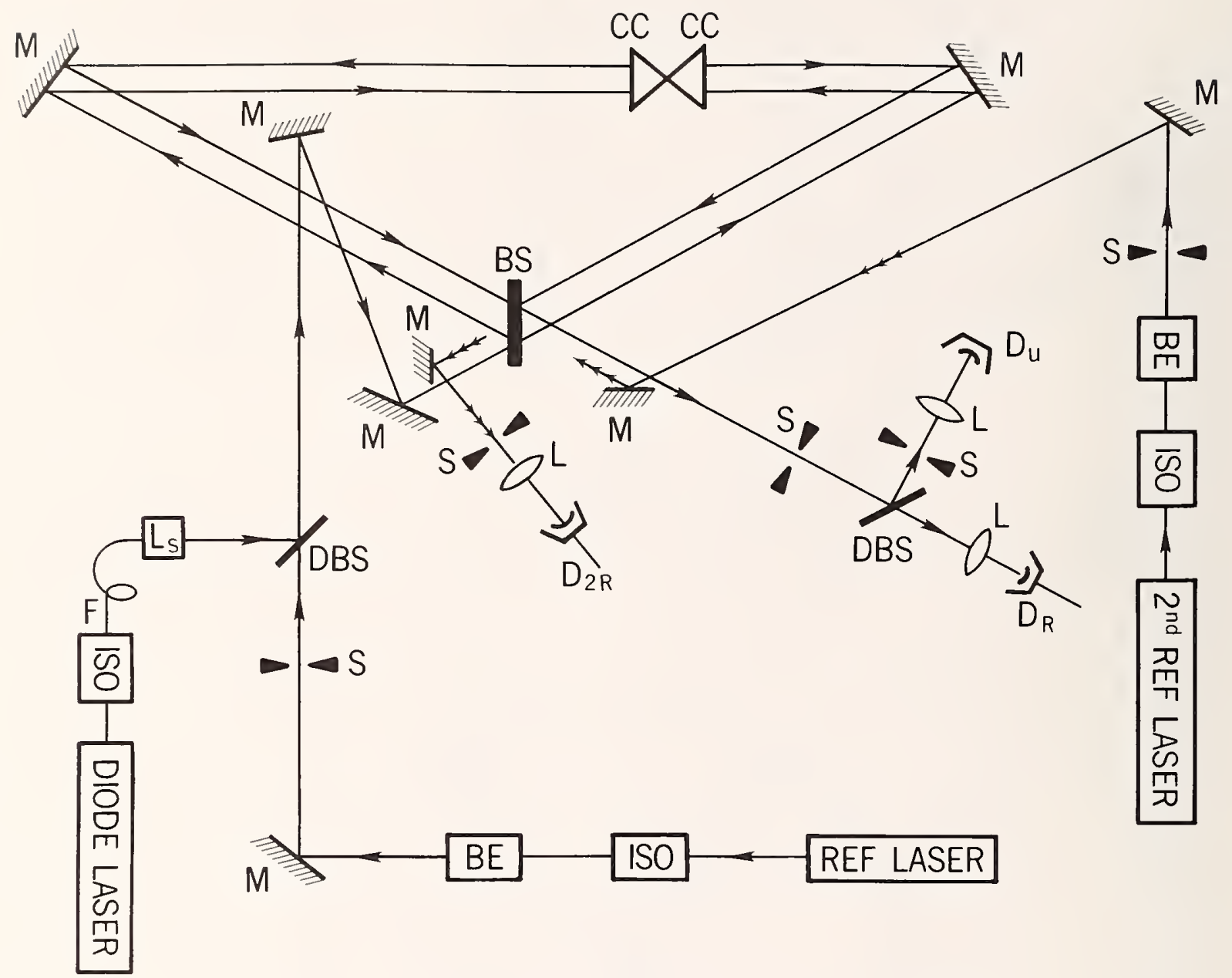

Figure 4. Schematic of components making up the optical system. We have $\mathrm{CC} \approx$ corner cubes, $\mathrm{M} \approx$ mirrors, $\mathrm{BS} \approx$ essential beamsplitter, $\mathrm{BE} \approx$ beam expanders, ISO $\approx$ optical isolators, $\mathrm{L} \approx$ lenses, $\mathrm{F} \approx$ single-mode fiber, $\mathrm{L}_{\mathrm{s}} \approx$ diode laser collimating lens system, $\mathrm{S} \approx$ shutters, $\mathrm{DBS} \approx$ dichroic beamsplitters/joiners, and $D_{R}, D_{2 R}, D_{U} \approx$ detectors. (The path of the second reference laser is parallel but not colinear to the main reference laser and is only used for system calibration.) 


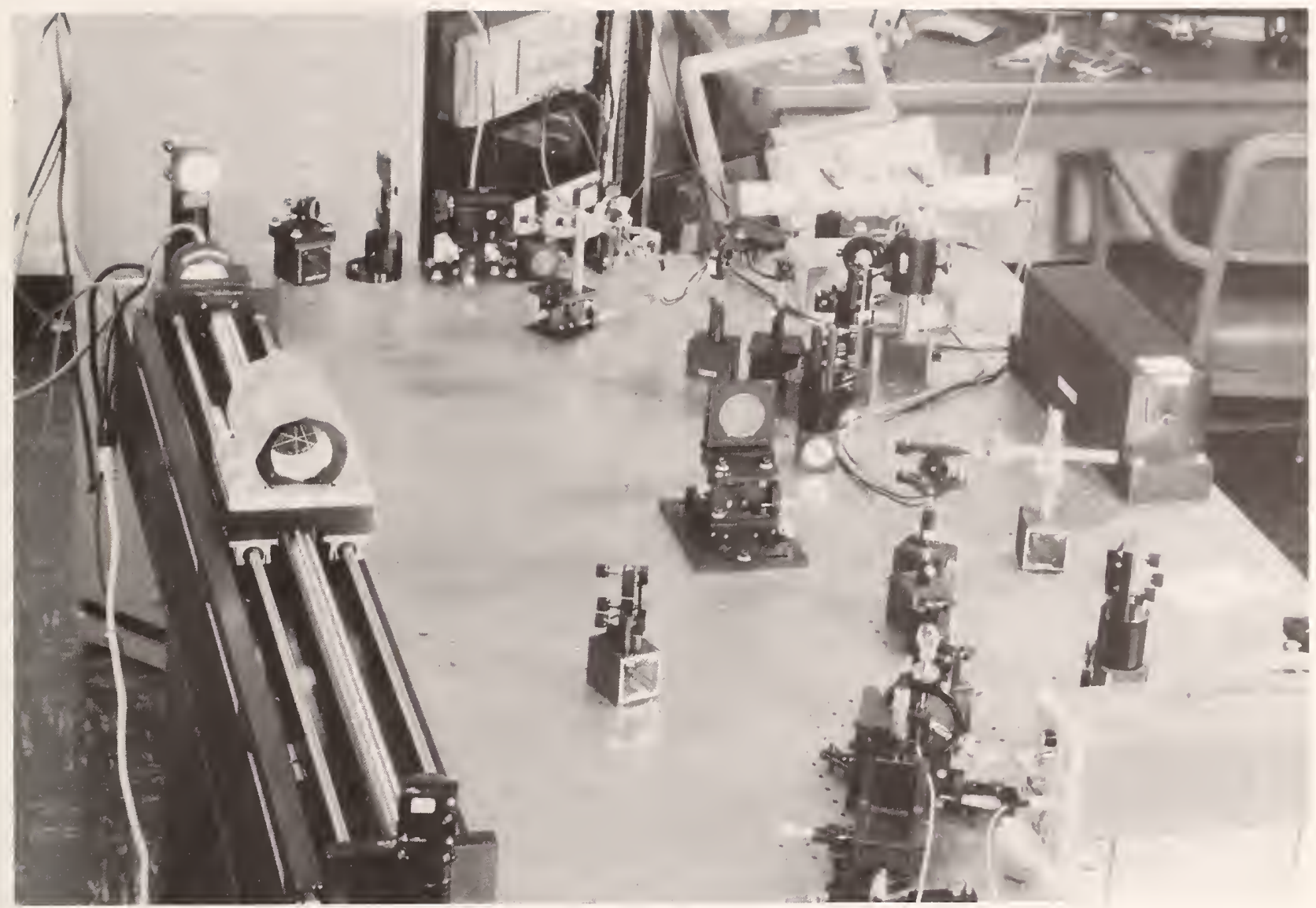

Figure 5. Lambdameter.

\subsection{Reference Laser}

The HeNe reference laser used in this lambdameter is frequencystabilized by a polarization technique, and can lock onto either the red or blue side of line center in the Doppler gain profile. These two adjacent, orthogonally polarized modes oscillate simultaneously in the laser gain cavity. A polarizing cube beamsplitter separates the modes, illuminating a photodiode with one of them. Down the beam path a nonpolarizing dielectric beamsplitter diverts about 20 percent of the remaining mode to a second photodiode. The two photodiode signals are sent to a differential comparator circuit, whose output is converted to a high-current signal and sent to a thermofoil heater in contact with the laser tube. As the laser cavity tunes by thermal expansion from the heater element, the intensities of the two polarization modes vary over the Doppler gain profile. When one mode is at a maximum, the second mode is a minimum. The comparator locks in when the two mode intensities differ by a preset amount. This maintains the heater current at the preset level and keeps the cavity length tuned to a specified resonance frequency. 
The manufacturer measured the two frequencies of a random sample of these HeNe's by comparing them with a master laser locked to one of the known transitions in molecular iodine. These measurements were performed on several of the lasers at JILA (Joint Institutes for Laboratory Astrophysics) [33] before they were made available commercially. The two frequencies are reported to be $\left(\begin{array}{ll}473 \quad 612 & 298 \pm 6\end{array}\right) \mathrm{MHz}$ and $(473613085$ $\pm 6) \mathrm{MHz}$. Taking the speed of light in vacuum to be $\mathrm{c}=299792458 \mathrm{~m} / \mathrm{s}$, the corresponding vacuum wavelengths are

$$
\begin{aligned}
& \lambda_{r_{1}}=0.632991287 \pm 0.000000008 \mu \mathrm{m}, \\
& \lambda_{\mathrm{r} 2}=0.632990235 \pm 0.000000008 \mu \mathrm{m} .
\end{aligned}
$$

The uncertainty in lambdameter accuracy will be governed by the uncertainty in the reference wavelengths and the refractive indices. For our reference laser, the average of the two wavelengths remains stable within $1: 10^{8}$. Although the individual modes may drift when locked, they do so together, toward or away from line center. Therefore we develop a wavelength measurement technique which allows us to make use of this property (section 6.2 ).

The relative dispersion of these neighboring wavelengths can be calculated for dry air using eqs (24) and (6). The difference vanishes in the parts per trillion range, so that $n_{s}$ (red) $\approx n_{s}$ (blue) $\approx 1.000220354$. This is in agreement with our intuition.

\subsection{Photodetectors and Fringe-Signal Frequency Multipliers}

Initially, standard photodetector circuits were assembled for the reference and unknown fringe signals. The frequency of each signal is proportional to the speed of the corner cubes and is a constant in the range 10 to $100 \mathrm{kHz}$. Several different silicon detectors were tried successfully for the red HeNe beam. An indium gallium arsenide photodetector was chosen for the $1.52 \mu \mathrm{m}$ laser because of its large active area ( $3 \mathrm{~mm}$ diameter). A germanium detector with an active area of $1 \mathrm{~mm}^{2}$ also worked as well. Since our counter counts pulses in only one direction (positive or negative slope), system accuracy could be doubled by adding devices that count the zero crossings for each fringe signal [34]. These were made using a bidirectional one-shot logic chip. For a sinusoidally varying fringe-signal input, the chip can be made to emit pulses of selectable width every time the input crosses a preset level, usually zero. At first, circuits which were distinct from the photodetector circuits were made using separate power supplies as well. These had a variable resistor which controlled the pulse width. Lambdameter accuracy was observed in the $0.1 \mathrm{ppm}$ range at the $0.63 \mu \mathrm{m}$ HeNe line using these devices. However, these devices were somewhat unstable because of lack of a solid ground plane and the finite cable length joining them to the photodetector boxes. Later, specially designed devices [34] which were professionally fabricated were purchased. These combined the photodetector and zero-crossing circuitry onto a small printed circuit board 
( $3 \mathrm{~cm} \times 5 \mathrm{~cm}$ ), both circuit components receiving power from a single supply. The unit used for the IR signal had to be simply modified by addition of a voltage divider to lower the reverse bias voltage across the IR detector.

False counts in the detector devices were a problem for some time. Various filtering and shielding techniques had to be applied to the driver and motor used to power the rail table upon which the carriage moved. The original driver had a $20 \mathrm{kHz}$ switcher that leaked noise into the photodetectors along the power lines and through radiation in space. Filtering the power line input into the driver and shielding the cable from the driver to the motor significantly reduced noise levels. However, we concluded that the driver should be housed in a Faraday cage with all inputs and ouputs shielded, including the cable from the indexer (described below). It was simpler to find a driver-motor system with satisfactory noise. False counting due to environmental high-frequency noise was eliminated by proper grounding of the optical table and removal of ground loops between it and other equipment such as the counter, motion control instrumentation, and laser power supplies.

\subsection{Instrumentation and Optical Components}

The retroreflectors are mounted on the carriage of a precision rail table having a $1.22 \mathrm{~m}$ scan distance. The unit employs a precisionground ball screw instead of a typical rolled screw. Travel limit switches prevent collision of the carriage with the ball-screw end mounts. The screw is connected to a rotary step motor driven by a linear microstep driver. The motion control system is conveniently operated by a digital indexer with push-button operation that controls carriage speed, amplitude of oscillation, and acceleration at endpoints. For our measurements carriage speed is $\approx 2$ to $3 \mathrm{~cm} / \mathrm{s}$. Operation at this speed gives the least mechanical vibrations of the retroreflectors; this vibration shows up as jitter in the fringe signals. Figure 6 below is a block diagram showing the motion control components, interferometer, and other relevant instrumentation.

The main beamsplitter for the interferometer is coated for $1.3 \mu \mathrm{m}$ radiation and wedged to eliminate unwanted reflections. At this wavelength, transmittance is about 46 percent for a P-polarization state with a $45 \mathrm{deg}$ angle of incidence. At $1.52 \mu \mathrm{m}$, $\mathrm{T}$ for an S-polarization is 29 percent and 73 percent for a P-polarization. For unpolarized light, $T$ is 51 percent. The reflectance and transmittance of the beamsplitter for $0.63 \mu \mathrm{m}$ HeNe light are about the same as plain glass. This is acceptable because of sufficient power output from these lasers. Equal beamsplitter/combiners are used at the interferometer entrance and exit to combine and separate the reference and unknown laser beams. These are coated for $1.55 \mu \mathrm{m}$, but without an antireflection coating. More than 80 percent of the $0.63 \mu \mathrm{m}$ reference laser beam is transmitted. More than 98 percent of the $1.5 \mu \mathrm{m}$ beam is reflected. The first high-reflection region is 10 percent of line center, which excludes wavelengths $\approx 1.3 \mu \mathrm{m}$. Thus additional splitter/combiners will be used for measurements at $1.3 \mu \mathrm{m}$. 


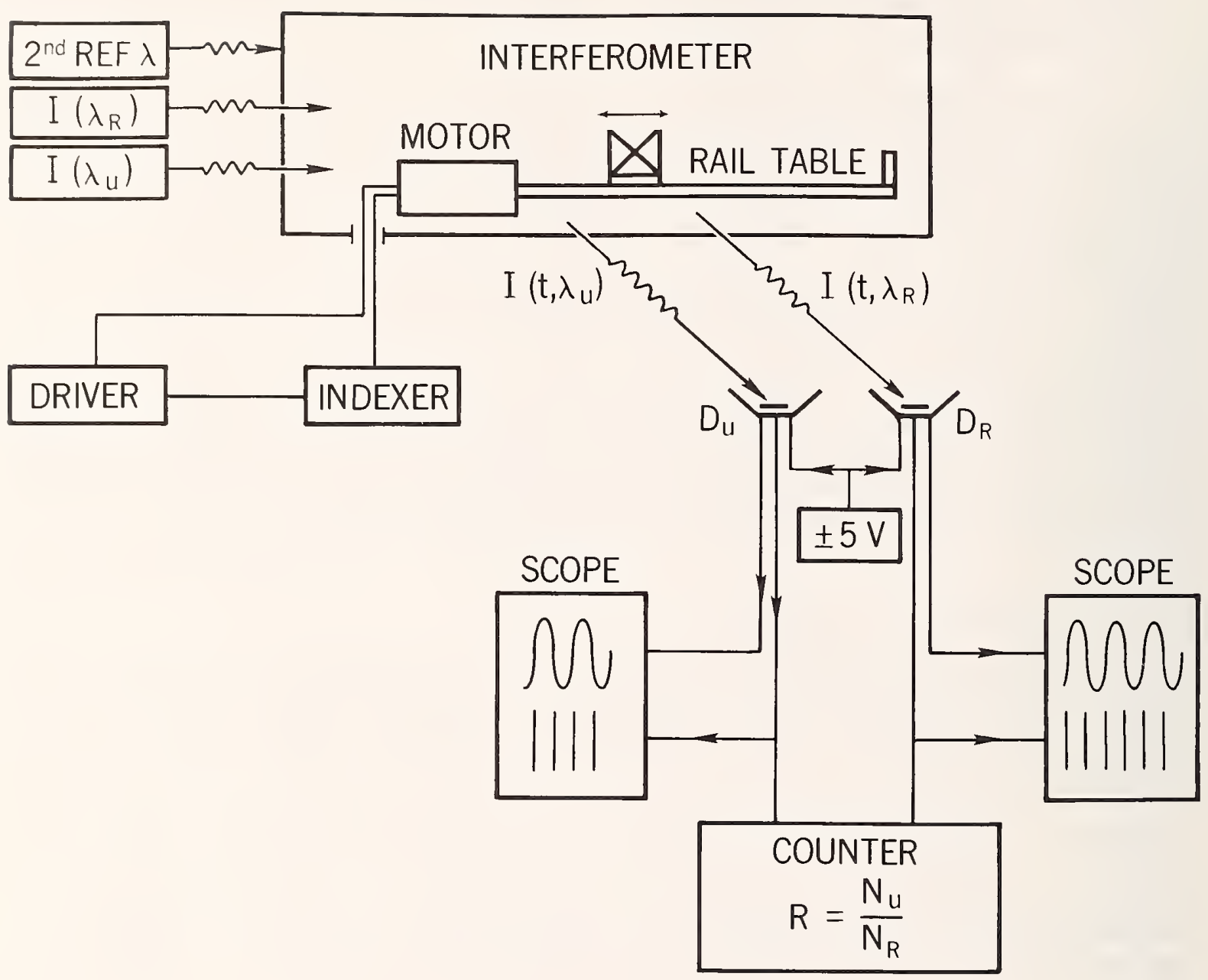

Figure 6. Block diagram showing system components.

Mirrors that had broadband infrared reflector coatings were purchased. These have high reflectivity at both 0.63 and $1.5 \mu \mathrm{m}$. The substrate material for the mirrors has negligible thermal expansion and is only slightly more expensive than standard materials. However, mirror mounts are made of standard aluminum, because it is very expensive to fabricate mounts from a material of negligible thermal expansion. Beam expanders for the reference lasers are standard, uncoated, with $10 \mathrm{x}$ expansion ratios. A Faraday rotator with $>30 \mathrm{~dB}$ isolation is used to optically isolate the main reference laser. This works better than a quarter-wave plate and polarizer. Isolation of the $1.52 \mu \mathrm{m}$ DFB laser diode is described in section 6.1 . 


\subsection{Optical Alignment of the System}

The first part of the alignment procedure is equivalent to that given in reference 33. The basic idea is similar to that for any Michelson interferometer using corner cubes. The visible reference beam is split into two beams which traverse distinct arms of the interferometer. The reflection from the beamsplitter, BS, is blocked, and the transmitted portion is reflected off mirror $M_{L}$ toward the carriage (with corner cubes). The beam is aligned parallel to the direction of motion of the carriage using $M_{L}$ and the entrance steering mirrors (fig. 2). The property of a corner cube is such that a beam entering one of its sextants reemerges antiparallel to the incident direction, but from the diametrically opposite sextant (fig. 3). When the carriage is near $\mathrm{M}_{\mathrm{L}}$, the entrance steering mirrors are adjusted so that the beam reflects from the corner cube and exits the system in a desirable direction. A colored circle of slightly smaller diameter than the beam's is drawn on a screen and placed in front of the photodetector and the exiting beam positioned so that the spot and beam are concentric. As the carriage approaches $M_{R}, M_{L}$ is adjusted to keep the beam concentric with the reference spot on the screen. In the beginning, concentric alignment of the spot and beam at one end of the motion results in misalignment of the two at the opposite end of the motion, so this is an iterative process which terminates when the alignment holds over the entire path of carriage motion. Then the transmitted beam is blocked and the beam reflected from BS is aligned as follows: when the carriage is near $M_{L}, M_{R}$ is adjusted to give concentricity between spot and beam; when the carriage is near $M_{R}$, BS is adjusted.

To speed up the alignment, a small screen with a colored spot can be taped to the corner-cube mount. Once the beam is incident upon the corner cube at a desired entry position, the spot is positioned to intercept the beam concentrically. The beam can be adjusted using the procedure above by scanning the carriage over the whole motion,

Inaccuracy in wavelength measurement due to optical misalignment of the lambdameter can be eliminated by superimposing the beams from the reference and unknown lasers so that they are colinear. The red and IR laser beams are arranged to be incident upon a dichroic beamsplitter/ combiner from perpendicular directions. This component reflects the IR light into the same direction as the red light which is transmitted. After the initial phase of the alignment procedure as outlined above, a mirror is placed before the beamsplitter at the entrance to the interferometer. This deflects the reference beam to a screen located at the opposite end of the room. The IR laser beam is then aligned using its own steering mirrors and the deflecting mirror so that it is concentric with the visible reference laser beam at a point just passed the combiner where the two are superimposed, and on the distant screen. This can be done using an IR-visible converter card. The amount of IR laser beam power at $1.5 \mu \mathrm{m}$ required to observe luminescence using one of these cards varies among different manufacturers by as much as 50 percent. In our case, low power output $(\approx 1 / 2 \mathrm{~mW})$ from our $1.52 \mu \mathrm{m}$ laser transmitter requires that we use the most sensitive card available. Once alignment 
is performed, the deflecting mirror is removed, and the beams traverse the interferometer almost colinearly. (The error due to misalignment is described in section 4.4.) Optical power losses in the IR beam may prevent alignment at the detector surface using a convertor card. In this case, the small portion of the visible reference beam that is reflected by the beamsplitter which separates the two beams can be used to finish the alignment. Also, an IR camera may be used if available.

\subsection{Measured Accuracy}

The accuracy of our system was tested in the visible portion of the spectrum by a scheme which uses the two adjacent modes on the red and blue sides of the peak of the Doppler gain profile of a frequencystabilized HeNe laser. The wavelength of a second frequency-stabilized HeNe laser of wavelength $\approx 0.63 \mu \mathrm{m}$ is measured with the reference laser locked on the blue side, and then the red side of the peak of the Doppler gain profile. As we now show, the result is independent of the wavelength of the second laser, as long as its wavelength is stable. If there is an instability within the measurement accuracy of our lambdameter, it will show up in the ratios.

Let $\nu$ (red), $\nu$ (blue) be the frequencies; $\lambda$ (red), $\lambda$ (blue) the vacuum wavelengths; and $\mathrm{n}$ (red), $\mathrm{n}$ (blue) the refractive indices of the red and blue shifted modes from the reference HeNe laser. Let $\lambda(S)$ be the vacuum wavelength of the second HeNe laser, $n(S)$ its refractive index, and $R$ the measured ratio of the wavelengths of the reference HeNe laser to the second HeNe laser in air. Finally, let $F$ be the ratio of frequencies of the reference HeNe laser, $F \equiv \nu$ (blue) $/ \nu($ red), and $Q$ the ratio of ratios, $\mathrm{Q} \equiv \mathrm{R}(\mathrm{red}) / \mathrm{R}$ (blue). Then

$$
F \equiv \frac{\nu(\text { blue })}{\nu(\text { red })}=1.000001662 \pm 0.000000025
$$

or,

$$
1.000001637 \leq F \leq 1.000001687 .
$$

Also,

$$
\begin{aligned}
R(\text { red }) & =\frac{\lambda(\text { red })}{\lambda(S)} \frac{n(S)}{n(\text { red })} \\
& =\frac{N(S)}{N(\text { red })}
\end{aligned}
$$

and

$$
\begin{aligned}
R(b \text { lue }) & =\frac{\lambda(\text { blue })}{\lambda(S)} \frac{n(S)}{n(b \text { lue })} \\
& =\frac{N(S)}{N(\text { blue })} .
\end{aligned}
$$


Now the quantity $\mathrm{n}$ (blue)/n(red) is very nearly 1 . Therefore,

$$
\begin{aligned}
Q \equiv \frac{R(\text { red })}{R(\text { blue })} & =\frac{\lambda(\text { red })}{\lambda(\text { blue })} \\
& =\frac{N(\text { blue })}{N(\text { red })} \\
& =\frac{\nu(\text { blue })}{\nu(\text { red })}
\end{aligned}
$$

It is critical that $Q$ be independent of any path difference between the reference and second HeNe lasers. Since the laser beams are not colinear, there will be some misalignment. Our result shows that $Q$ is independent of the number of fringes counted for the second laser, and hence independent of the path. It is necessary only that the path of the second laser beam remain constant over the time for corresponding sets of measurements, and this is the case.

In table 3 we see a typical set of measurements for both $R$ (red) and $\mathrm{R}$ (blue). Let $\langle\mathrm{R}($ red $)\rangle$ and $\langle\mathrm{R}$ (blue) $\rangle$ be the average values for each set. Then

$$
\frac{<\mathrm{R}(\text { red })>}{<\mathrm{R}(\text { blue })>}=1.00000166
$$

From the averages shown in the table, $Q=1.00000166$. The number of zero crossings counted is $\approx 14 \cdot 10^{6}$, giving an accuracy of $\approx 0.7: 10^{7}$. This establishes the mechanical stability of the system for measurements at other wavelengths. Because the value for a ratio measurement is very nearly equal to unity, a change in the ratio of one part in ten million

\begin{tabular}{|c|c|c|}
\hline & $R($ red $)$ & $\mathrm{R}$ (blue) \\
\hline & 1.0000004 & 0.9999987 \\
\hline & 1.0000004 & 0.9999988 \\
\hline & 1.0000004 & 0.9999988 \\
\hline & 1.0000004 & 0.9999988 \\
\hline & 1.0000004 & 0.9999987 \\
\hline & 1.0000004 & 0.9999987 \\
\hline & 1.0000004 & 0.9999987 \\
\hline & 1.0000004 & 0.9999987 \\
\hline & 1.0000004 & 0.9999988 \\
\hline & 1.0000004 & 0.9999987 \\
\hline $\operatorname{Avg} \pm \sigma$ & $1.00000004 \pm 0.0$ & $0.99999874 \pm 0.52 \cdot 10^{-7}$ \\
\hline
\end{tabular}
corresponds to a fractional uncertainty in the ratio of one part in ten million.

Table 3. Typical sets of 10 measurements for $R$ (red) and R(blue). 


\section{Wavelength Measurements on a Single-Mode Diode Laser Source}

Single-mode laser diodes for optical communication systems have fairly narrow linewidths and low optical output power. But there is an increasing demand for narrower linewidths and higher optical power than what is presently available commercially, especially when considering coherent systems. Many laboratories around the world are working to achieve these goals. Both DBR and DFB diode lasers are finding applications in this field. Some recent advances in this area were presented at the 1989 CLEO/QELS conference. Koch [35] reported fabrication of DBR lasers having linewidths as low as $1.9 \mathrm{MHz}$, with $1.2 \mathrm{MHz}$ possible. These had 1 to $2 \mathrm{~mW}$ optical power and were tunable over $8 \mathrm{~nm}$. Attempts at wider range tuning increased linewidth. Tohmori et al. [36] fabricated a butt-jointed DBR with a minimum linewidth of $1 \mathrm{MHz}$ and a wavelength of $1.48 \mu \mathrm{m}$. Linewidth increased to 2 to $4 \mathrm{MHz}$ as the wavelength was tuned over $40 \mathrm{~nm}$. Optical power was $18 \mathrm{~mW}$. A tunable MQW-DBR laser was reported by Hernandez-Gil et al. [37]. The lasing wavelength was $1.5 \mu \mathrm{m}$ with a linewidth of $3 \mathrm{MHz}$. Wang et al. [38] report a DFB laser with 10 $\mathrm{MHz}$ linewidth and $6 \mathrm{~mW}$ output power at a wavelength of $1.3 \mu \mathrm{m}$. DFB lasers with wavelengths of 1.3 and $1.55 \mu \mathrm{m}$ and linewidths less than 10 $\mathrm{MHz}$ were reported by Mito and Kitamura [39]. Mihara and Otobe [40] developed an AlGaAs DFB laser at $0.8 \mu \mathrm{m}$ with linewidth of $4.2 \mathrm{MHz}$ and $8 \mathrm{~mW}$. A minimum linewidth of $1.5 \mathrm{MHZ}$ was achieved for a multiple quantum well DFB fabricated by Kojima et al. [41]. The wavelength was $866.5 \mathrm{~nm}$. Finally, frequency stabilization of a DFB laser module within $0.5 \mathrm{MHz}$ was achieved using the $1.53159 \mu \mathrm{m}$ vibrational-rotational absorption line of acetylene by Sudo et al. [42]. For acetylene gas between $-35^{\circ} \mathrm{C}$ and $70^{\circ} \mathrm{C}$, the temperature dependence of the absorption peak wavelength is $\approx 0.1 \mathrm{MHz} /{ }^{\circ} \mathrm{C}$. This results in a highly stable source with a small temperature dependence.

\subsection{Description of the $1.52 \mu \mathrm{m}$ Diode Laser}

Measurements reported in this paper were made on a high-speed diode laser transmitter operating in the continuous-wave mode. The source is a GaInAsP DFB diode laser packaged in a plug-in module. Power is supplied from a mainframe supplied as part of the unit. The laser diode and fiber are joined through a laser welding process and hermetically sealed to achieve high stability. The laser beam emerges through a biconic connector on the front of the module, but can be harnessed directly using collimating lenses. Initially, we chose a single-mode fiber with a biconic connector at one end for connection to the transmitter. Because of instability arising from retroreflections into the laser diode, we switched to a single-mode fiber having an isolator built into it. The beam emerging from the fiber is collimated with a diode laser collimating lens that is coated for $1.53 \mu \mathrm{m}$. The transmitter has its own current supply and temperature stabilization system. A thermistor attached to the laser and its submount monitors temperature, which is maintained at a preset value by a thermoelectric cooler. Spectral linewidth in the $\mathrm{cw}$, unmodulated mode is $<100 \mathrm{MHz}$, which is $<10^{-6} \mu \mathrm{m}$. Wavelength dependence with temperature is $\approx 0.1 \mathrm{~nm} /{ }^{\circ} \mathrm{C}$. Minimum threshold current is typically 
$\approx 30 \mathrm{~mA}$. Side-mode suppression is $>30 \mathrm{~dB}$. Before purchase, emission wavelength is specified by the manufacturer to be in the range of 1500 to $1570 \mathrm{~nm}$. For our unit the manufacturer specified the wavelength to be $1.5205 \mu \mathrm{m}$. The specifications above are from the manual accompanying the transmitter. We measured the optical power output to be $0.384 \mathrm{~mW}$ using an optical average-power meter.

\subsection{Results of Wavelength Measurements}

The average center wavelength of the two independent modes of the reference HeNe laser is known to $1: 10^{8}$ (section 5.2). To use this property of the reference laser we adopt the following scheme: we measure the wavelength of the unknown laser with the reference laser locked to the blue side of the peak of the Doppler gain profile. This gives

$$
R(\text { blue })=\frac{N(L D)}{N(\text { blue })}=\frac{\lambda(\text { blue })}{n(\text { blue }) \lambda_{u}\left(n_{u}\right)}
$$

We then switch the reference laser to the red side and take more measurements. This gives

$$
R(\text { red })=\frac{N(L D)}{N(\text { red })}=\frac{\lambda(\text { red })}{n(\text { red }) \lambda_{u}\left(n_{u}\right)}
$$

The unknown wavelength is then

$$
\lambda_{\mathrm{u}}=\frac{\lambda(\text { red }) / \mathrm{n}(\text { red })+\lambda(\text { blue }) / \mathrm{n}(\mathrm{blue})}{\mathrm{R}(\text { red })+\mathrm{R}(\mathrm{blue})} .
$$

Since $\mathrm{n}(\mathrm{blue}) \approx \mathrm{n}($ red $) \equiv \mathrm{n}($ ref $)$, we write

$$
\lambda_{u}=\frac{\lambda(\text { red })+\lambda(\text { blue })}{n(\text { ref })[R(\text { red })+R(\text { blue })]} .
$$

The wavelength in air is found from eq (32) above and eqs (6-8) for the dispersion.

The fractional uncertainty in the wavelength can be found from the measurements by simply calculating the fractional uncertainty in the ratio, $\delta R / R$. The counter error, which we approximate by $1 / N$ for the reference laser, is $\left\langle 10^{-7}\right.$ and can be neglected in comparison with the observed physical fluctuations due to temperature, injection current, and possibly optical feedback. Thus the fractional uncertainty in the diode laser's wavelength reduces to $\delta R / R$.

To test the wavemeter's precision at various points of the scan, but excluding the endpoints, two sets of twelve ratio measurements were taken with a $4 \mathrm{~s}$ gate time. This is approximately one-tenth of the time for a complete scan and resulted in a counter display of six digits. This 
corresponded to a wavelength accuracy in the parts-per-million range. (The reference laser was set on the blue side.) Table 4 below shows that wavelength stability of the laser diode may exceed $1 \mathrm{ppm}$ and that instrument resolution is at least this high.

Table 4. Ratio measurements for a $1.52 \mu \mathrm{m}$ DFB diode laser relative to a stabilized HeNe. The $4 \mathrm{~s}$ gate time resulted in an accuracy of $1 \mathrm{ppm}$. The numbers show that source stability and instrument resolution are at least this high.

\begin{tabular}{cc}
\hline Set 1 & Set 2 \\
\hline 0.416103 & 0.416104 \\
0.416103 & 0.416104 \\
0.416103 & 0.416103 \\
0.416103 & 0.416104 \\
0.416103 & 0.416103 \\
0.416104 & 0.416107 \\
0.416104 & 0.416104 \\
0.416103 & 0.416104 \\
0.416104 & 0.416105 \\
0.416104 & 0.416103 \\
0.416104 & 0.416103 \\
0.416104 & 0.416104 \\
\hline
\end{tabular}

To insure that retroreflections did not destabilize the laser diode during the time of a measurement, a single fringe of the interference signal was observed on an oscilloscope. The pulse width was $\approx 30 \mathrm{~ns}$. If the pulse flickered, presumably due to a stray reflection, data were discarded. This was justified because it was possible to orient the Faraday isolator so as to eliminate all flickers for periods of several hours. Eventually the isolator was positioned off the optical table to isolate it from mechanical vibrations caused by the motion control system for the scanning corner cubes. Also, merely touching the fiber or isolator resulted in severe signal instability. Thus we assume that the diode laser's wavelength was affected by the intensity and phase of the optical feedback that it received at any given time. The primary source of optical feedback most likely resides at the biconic connector output on the transmitter.

Four sets of measurements were taken with a $40 \mathrm{~s}$ gate time corresponding to an accuracy of $\approx 2: 10^{7}$. Table 5 shows two sets of data with the reference laser locked to the red side of the Doppler gain profile; for the other two sets it is locked to the blue side. Wavelength instability is $< \pm 1 \mathrm{ppm}$. 
Table 5. Ratio measurements (day 1) for the $1.52 \mu \mathrm{m}$ laser using a $40 \mathrm{~s}$ gate time. In sets 1 and 3 the reference laser is locked to the red side of the peak of the Doppler gain profile. In sets 2 and 4 it is locked to the blue side. Laser diode instability is $< \pm 1: 10^{6}$.

\begin{tabular}{|c|c|}
\hline Set 1 (Red $s$ & Set 2 (Blue side) \\
\hline 0.4161053 & 0.4161044 \\
\hline 0.4161053 & 0.4161045 \\
\hline 0.4161052 & 0.4161044 \\
\hline 0.4161050 & 0.4161042 \\
\hline 0.4161051 & 0.4161049 \\
\hline 0.4161051 & 0.4161046 \\
\hline 0.4161049 & 0.4161048 \\
\hline 0.4161055 & 0.4161043 \\
\hline 0.4161048 & 0.4161045 \\
\hline 0.4161051 & 0.4161046 \\
\hline$\langle\mathrm{R}\rangle=0.4161052$ & $\langle\mathrm{R}\rangle=0.4161045$ \\
\hline \multicolumn{2}{|c|}{ Set 3 (Red side) } \\
\hline 0.4161050 & 0.4161044 \\
\hline 0.4161053 & 0.4161045 \\
\hline 0.4161050 & 0.4161045 \\
\hline 0.4161055 & 0.4161045 \\
\hline 0.4161049 & 0.4161043 \\
\hline 0.4161054 & 0.4161048 \\
\hline 0.4161052 & 0.4161048 \\
\hline 0.4161052 & 0.4161048 \\
\hline 0.4161054 & 0.4161047 \\
\hline 0.4161049 & 0.4161045 \\
\hline$\langle R\rangle=0.4161052$ & $\langle R\rangle=0.4161046$ \\
\hline
\end{tabular}

Using eq (31) and the averages for $\langle R\rangle$ above, we estimate the average wavelength of the diode laser at $\mathrm{T}=23^{\circ} \mathrm{C}, \mathrm{P}=82922.28 \mathrm{~Pa}$ (622 Torr), to be

$$
\lambda=1.521089 \pm \epsilon \mu \mathrm{m} .
$$

where $\epsilon$ is the uncertainty due to instrumental error, wavelength instability arising from fluctuations in physical parameters such as temperature and injection current, and optical feedback. Instrumental error has been estimated to be $< \pm 2: 10^{7}$. Since $\epsilon$ is not a random variable, we cannot define a standard deviation of the mean. From these data we conclude that the short-term instability of our DFB diode laser is $\leq 1 \mathrm{ppm}$. 
More measurements were taken (day 2) with the room lights off. The results are shown in table 6 . The ratios obtained for both the blue and red sides are higher than for the previous day. This corresponds to a slightly smaller average value for the unknown wavelength and probably arises from differences in room temperature or injection current from day to day. Although approximate room temperature was recorded and found to vary by a few degrees Celsius from day to day, an accurate record is useless because the manufacturer cannot provide data on temperature changes of their laser for small changes in ambient temperature. (They specify laser temperature stability, resulting from their temperature control system, to be $\Delta \mathrm{T} \approx \pm 1{ }^{\circ} \mathrm{C}$ over the full operating range of $-15^{\circ} \mathrm{C}$ $\leq \mathrm{T} \leq+65^{\circ} \mathrm{C}$. ) Finally, table 7 shows ratio measurements taken on yet another day. These are in agreement with the values shown in table 5 . Additional ratio measurements are given in appendix A.

Table 6. Ratio measurements whose values are greater than for the previous set taken on a different day. These correspond to a slightly smaller average value for the DFB laser diode wavelength.

\begin{tabular}{cc}
\hline Set 1 (blue side) & Set 2 (blue side) \\
\hline 0.4161052 & 0.4161053 \\
0.4161050 & 0.4161055 \\
0.4161049 & 0.4161054 \\
0.4161048 & 0.4161051 \\
0.4161050 & 0.4161052 \\
0.4161051 & 0.4161049 \\
0.4161056 & 0.4161055 \\
0.4161050 & 0.4161046 \\
0.4161049 & 0.4161047 \\
0.4161051 & 0.4161049 \\
$\langle\mathrm{R}>=0.4161051$ & $<\mathrm{R}>=0.4161051$ \\
\hline Set $3($ red side & Set 4 (blue side) \\
\hline 0.4161058 & 0.4161050 \\
0.4161057 & 0.4161046 \\
0.4161056 & 0.4161057 \\
0.4161056 & 0.4161049 \\
0.4161065 & 0.4161054 \\
0.4161059 & 0.4161053 \\
0.4161055 & 0.4161048 \\
0.4161059 & 0.4161052 \\
0.4161057 & 0.4161058 \\
0.4161061 & 0.4161051 \\
$\langle\mathrm{R}>=0.4161058$ & \\
\hline & $<=0.4161052$ \\
\hline &
\end{tabular}




\begin{tabular}{cc}
\hline Set 5 (red side) & Set 6 (red side) \\
\hline 0.4161056 & 0.4161054 \\
0.4161057 & 0.4161055 \\
0.4161057 & 0.4161052 \\
0.4161062 & 0.4161059 \\
0.4161053 & 0.4161063 \\
0.4161058 & 0.4161060 \\
0.4161056 & 0.4161057 \\
0.4161055 & 0.4161058 \\
0.4161069 & 0.4161056 \\
0.4161054 & 0.4161055 \\
$\langle\mathrm{R}>=0.4161056$ & \\
Set 7 (b1ue side) $>=0.4161057$ \\
0.4161047 & \\
0.4161052 & \\
0.4161053 & \\
0.4161054 & \\
0.4161050 & \\
0.4161051 & \\
0.4161051 & \\
0.4161056 & \\
0.4161054 & \\
$\langle\mathrm{R}>=0.4161052$ & \\
\hline
\end{tabular}


Table 7. Ratio measurements taken on day 3 agree with those in table 5. Note that Set 6 has only seven measurements. This is because the DFB laser destabilized at that time and the measurement was stopped.

\begin{tabular}{|c|c|}
\hline Set 1 (blue side) & Set 2 (red side) \\
\hline 0.4161045 & 0.4161051 \\
\hline 0.4161041 & 0.4161054 \\
\hline 0.4161044 & 0.4161052 \\
\hline 0.4161049 & 0.4161048 \\
\hline 0.4161046 & 0.4161054 \\
\hline 0.4161043 & 0.4161049 \\
\hline 0.4161044 & 0.4161050 \\
\hline 0.4161041 & 0.4161052 \\
\hline 0.4161042 & 0.4161051 \\
\hline 0.4161042 & 0.4161058 \\
\hline$\langle\mathrm{R}\rangle=0.4161044$ & $\langle\mathrm{R}\rangle=0.4161052$ \\
\hline Set 3 (red side) & Set 4 (blue side) \\
\hline 0.4161057 & 0.4161048 \\
\hline 0.4161053 & 0.4161049 \\
\hline 0.4161054 & 0.4161051 \\
\hline 0.4161057 & 0.4161048 \\
\hline 0.4161056 & 0.4161043 \\
\hline 0.4161060 & 0.4161046 \\
\hline 0.4161052 & 0.4161047 \\
\hline 0.4161058 & 0.4161045 \\
\hline 0.4161057 & 0.4161050 \\
\hline 0.4161062 & 0.4161049 \\
\hline$\langle\mathrm{R}\rangle=0.4161056$ & $\langle\mathrm{R}\rangle=0.4161048$ \\
\hline Set 5 (red side) & Set 6 (blue side) \\
\hline 0.4161056 & 0.4161048 \\
\hline 0.4161058 & 0.4161046 \\
\hline 0.4161057 & 0.4161044 \\
\hline 0.4161056 & 0.4161049 \\
\hline 0.4161057 & 0.4161048 \\
\hline 0.4161056 & 0.4161050 \\
\hline 0.4161057 & 0.4161050 \\
\hline 0.4161055 & \\
\hline 0.4161059 & $\langle R\rangle=0.4161048$ \\
\hline 0.4161060 & \\
\hline$\langle\mathrm{R}\rangle=0.4161057$ & \\
\hline
\end{tabular}


A lambdameter which measures the wavelength of sources used in optical fiber communications has been built. An accuracy of $<0.1 \mathrm{ppm}$ has been observed at the $0.63 \mu \mathrm{m}$ HeNe line. From this we deduce an accuracy of $\approx 0.2 \mathrm{ppm}$ in the near infrared. Averaging could increase accuracy further for highly stable sources. Instability of the $1.52 \mu \mathrm{m}$ DFB diode laser source was in the range $\pm 1 \mathrm{ppm}$. This is likely to be a result of fluctuations in temperature or injection current. However, optical feedback into the diode laser from the biconic connector-fiber output interface intermittantly caused significant signal instability. An index-matching gel which should eliminate this feedback reflection is being ordered. Also, one or more additional optical isolators will be added to reduce fiber and other component sources of feedback from the interferometer to $\approx 60 \mathrm{~dB}$. Introduction of radiation from the unknown source into the interferometer without the fiber is under consideration.

\section{Acknowledgments}

I thank Bob Drullinger for illuminating discussions on lambdameters, and for supplying fine photodetector devices having zero-crossing signal frequency multipliers built into them. I am grateful to Doug Franzen for suggesting the HeNe reference laser that oscillates in either one of two adjacent cavity modes, and for other useful discussions. Also, thanks to Leo Holberg for some interesting conversations related to this research and to Edie DeWeese for preparing the final manuscript.

9. References

[1] Hall, J.L. and Lee, S.A., Interferometric Real-time Display of CW Dye Laser Wavelength with Sub-Doppler Accuracy. Appl. Phys. Lett. $29(6)$ : $367-369 ; 1976$ September 15.

[2] Bennett, S.J., and Gill, P. A Digital Interferometer for Wavelength Measurement. J. Phys. E, 13: 174-177; 1980.

[3] Kowalski, J., Neumann, R., Noehte, S., Schwarzwald, R., Suhr, H., and $\mathrm{Zu}$ Putlitz, G. An Automatic Michelson Interferometer with Fringe Dropout Correction. Opt. Commun. 53(3): 141-146; 1985 March.

[4] Ishikawa, J., Nobuhiko, I., and Tanaka, K. Accurate Wavelength Meter for CW Lasers. Appl. Opt. 25(5: 639-643; 1986 March.

[5] Kowalski, F.V., Hawkins, R.T., and Schawlow, A.L., Digital Wavemeter for CW Lasers. J. Opt. Soc. Am. 66(9): 965-966; 1976 September. 
[6] Lee, S.A., and Hall, J.L. A Traveling Michelson Interferometer With Phase-Locked Fringe Interpolation, Laser Spectroscopy III. Hall, J.L., and Carlsten, J.L., eds. Proc., 3rd Intl. Conf., Berlin-Heidelberg: Springer-Verlag; 1977. 421-422.

[7] Kowalski, F.V., Teets, R.E., Demtroder, W., and Schawlow, A.L. An Improved Wavemeter for CW Lasers. J. Opt. Soc. Am. 68(11): 1611$1612 ; 1978$ November.

[8] Branberg, A., and Nylen, P. Vacuum-Operated Digital Wavelength Meter. Rev. Sci. Instrum. 56(2): 211-213; 1985 February.

[9] Edlen, B. The Refractive Index of Air. Metrologia 2(2): 71-80; 1966.

[10] Monchalin, J.-P., Kelly, M.J., Thomas, J.E., Kurnit, N.A., Szoke, A., Zernike, F., Lee, P.H., and Javan, A. Accurate Laser Wavelength Measurement with a Precision Two-beam Scanning Michelson Interferometer. Appl. Opt. 20(5): 736-757; 1981 March.

[11] Bonsch, G. Wavelength Ratio of Stabilized Laser Radiation at $3.39 \mu \mathrm{m}$ and $0.633 \mu \mathrm{m}$. Appl. Opt. 22(21): 3414-3419; 1983 November.

[12] Bonsch, G. Simultaneous Wavelength Comparison of IodineStabilized Lasers at $515 \mathrm{~nm}, 633 \mathrm{~nm}$, and $640 \mathrm{~nm}$. IEEE Trans. Instrum. Meas. IM-34(2): 248-251; 1985 June.

[13] Kahane, A., O'Sullivan, M.S., Sanford, N.M., and Stoicheff, B.P. Vernier Fringe-counting Device for Laser Wavelength Measurements. Rev. Sci. Instrum. 54(9): 1138-1142; 1983 September.

[14] Salimbeni, R., and Pole, R.V. Compact High-accuracy Wavemeter. Opt. Lett. 5(2): 39-41; 1980 February.

[15] Ishikawa, J. Accurate Optical Alignment with a Single-mode Optical Fiber. Appl. Opt. 25(18): 3013-3014; 1986 September.

[16] Junttila, M-L., Stahlberg, B., Kyro, E., Veijola, T., Kauppinen, J . Fourier Transform Wavemeter. Rev. Sci. Instrum. 58(7): 1180$1184 ; 1987$ July.

[17] Cachenaut, J., Man, C., Cerez, P., Brillet, A., Stoeckel, F., Jourdan, A., and Hartmann, F. Description and Accuracy Tests of an Improved Lambdameter. Rev. Phys. Appl. 14: 685-688; 1979 June.

[18] Mulders, J.J.L., Steeman, P.A.M., Kemper, A.H. and Steenhuysen, L.W.G. Electronic Improvement of Interferometric Measurement of Dye Laser Wavelengths. Opt. Laser Tech., pp. 193-196; 1985 August. 
[19] Rowley, W.R.C., Shotton, K.C., and Woods, P.T. A Simple MovingCarriage Interferometer for 1 in $10^{7}$ Wavelength Intercomparison, and a Servocontrolled Fabry-Perot System For 3 in $10^{11}$ Accuracy. Hall, J.L., and Carlsten, J.L., eds. Laser Spectroscopy III, Proc., 3rd Intl. Conf., Berlin-Heidelberg: Springer-Verlag; 1977. $425-426$.

[20] Evans, W.J., and Lambert, D.K. Wavemeter for Lead-salt Diode Laser Calibration. Appl. Opt. 25(17): 2867-2868; 1986 September.

[21] Murty, M.V.R.K. Some More Aspects of the Michelson

Interferometer with Cube Corners. J. Opt. Soc. Am. 50(1): 7-10; 1960 January.

[22] Murty, M.V.R.K. Modification of Michelson Interferometer using only One Cube-Corner Prism. J. Opt. Soc. Am. 50(1): 83-84; 1960 January.

[23] Hui-Rong, X., Benson, S.V., and Hansch, T.W. A "Toy Train Wavemeter." Laser Focus, pp. 54-58; 1981 March.

[24] Milan, C., Pullicino, M., Roussel, G., and Moret-Baily, J. Realisation d'un Lambdametre. J. Opt. (Paris), 15(1): 31-41; 1984.

[25] Lawrence, M. Continuous Wave Laser Wavelength Measurement using the Travelling Michelson Interferometer. Opt. Laser Tech., pp. 137-140; 1984 June.

[26] Snyder, J.J. Laser Wavelength Meters. Laser Focus, pp. 55-61; 1982 May.

[27] Estler, W.T. High-Accuracy Displacement Interferometry in Air. Appl. Opt. 24(6): 808-815; 1985 March.

[28] Popela, B. The Influence of the Atmosphere on the Wavelength of the He-Ne Laser and the Solution of Corrections of the Laser Interferometer. Opt. Acta 19(7): 605-612; 1972.

[29] Hill, R.J., Clifford, S.F., and Lawrence, R.S. Refractive-index and Absorption Fluctuations in the Infrared Caused by Temperature, Humidity, and Pressure Fluctuations. J. Opt. Soc. Am. 70(10): $1192-1205 ; 1980$ October.

[30] Jones, F.E. The Refractivity of Air. J. Res. Nat. Bur. Stand. (U.S.) 86(1): 27-32; 1980 July.

[31] Peck, E.R., and Reeder, K. Dispersion of Air. J. Opt. Soc. Amer. 62(8): 958-962; 1972 August.

[32] Schlatter, T. Private communications, National Institute of Standards and Technology, 325 Broadway, Boulder, Colorado 80303; 1989. 
[33] Barger, R. Private communications, Joint Institute for Laboratory Astrophysics, Boulder, Colorado; now with Newport Corp., $18235 \mathrm{Mt}$. Baldy Circle, Fountain Valley, California; 1989.

[34] Drullinger, R. Private communications and personal notes on the lambdameter, National Institute of Standards and Technology, 325 Broadway, Boulder, Colorado 80303.

[35] Koch, T. Tunable Multiple Quantum Well Distributed Bragg Reflector Lasers. QELS 89, 1989 April 24-28; Baltimore, MD, 1989; Paper TuJJ $1 ; 1989$.

[36] Tohmori, Y., Kano, F., Kondo, Y., Fukuda, M., Nakao, M., Sato, K., and Oe, K. Wavelength Tuning with Narrow Linewidth $(2 \approx 4)$ in High Power Operating Butt-Jointed Distributed Bragg Reflector Lasers. CLEO 89, 1989 April 24-28; Baltimore, Maryland, Postdeadline Paper PD $15 ; 1989$.

[37] Hernandez-Gil, F., Koch, T., Koren, U., Gnall, R., and Burrus, C. A Tunable MQW-DBR Laser with a Monolithically Integrated InGaAsP/InP Directional Coupler Switch. CLEO 89, 1989 April 24-28; Baltimore, Maryland, Postdeadline Paper 17; 1989.

[38] Wang, S., Dutta, N., and Gnauck, A. Wide Bandwidth and High Power $1.3 \mu \mathrm{m}$ InGaAsP Buried Heterostructure Distributed Feedback Lasers. CLEO 89, 1989 April 24-28; Baltimore, Maryland, Paper TuD 1: 50-51; 1989 .

[39] Mito, I., and Kitamura, K. GaInAs/GaInAsP Multiquantum Well DFB Lasers. CLEO 89, 1989 April 24-28; Baltimore, Maryland, Paper TuD 5: $52 ; 1989$.

[40] Mihara, K., and Otobe, T. High Speed Optical Transmission Capability and Long Coherence Length of AlGaAs Distributed Feedback Lasers. CLEO 89, 1989 April 24-28; Baltimore, Maryland, Paper TuJ 11 : $80-81 ; 1989$.

[41] Kojima, K., Hara, K., and Kyuma, K. Narrow Linewidth AlGaAs/GaAs Multiple Quantum Well Distributed Feedback Lasers. CLEO 89, 1989 April 24-28; Baltimore, Maryland, Paper WL 4: 238-239; 1989.

[42] Sudo, S., Sakai, Y., Yasaka, H., and Ikegami, T., FrequencyStabilized DFB Laser Module Using $1.53159 \mu \mathrm{m}$ Absorption Line of $\mathrm{C}_{2} \mathrm{H}_{2}$, IEEE Photonics Tech. Lett. 1(10): 281-284; October 1989. 
Appendix A. Raw Data From Diode Laser Wavelength Measurements

The ratio measurements below were taken with a 40 s gate time. Signal instability, presumably due to retroreflections, was observed about every tenth measurement as pulse flicker on an oscilloscope. The corresponding wild readings were discarded. Typical values were $\approx 0.4161000$. As can be seen from the data, the other values are consistent with those given in the tables of section 6.2.

\begin{tabular}{ll}
\hline Blue side & Red side \\
\hline 0.4161045 & 0.4161054 \\
0.4161044 & 0.4161051 \\
0.4161045 & 0.4161055 \\
0.4161044 & 0.4161055 \\
0.4161044 & 0.4161054 \\
0.4161047 & 0.4161050 \\
0.4161044 & 0.4161052 \\
0.4161047 & 0.4161053 \\
0.4161038 & 0.4161052 \\
0.4161048 & 0.4161053 \\
0.4161048 & 0.4161053 \\
0.4161046 & 0.4161044 \\
0.4161044 & 0.4161052 \\
0.4161046 & 0.4161055 \\
0.4161037 & 0.4161049 \\
0.4161047 & 0.4161052 \\
0.4161046 & 0.4161046 \\
0.4161043 & 0.4161052 \\
0.4161045 & 0.4161056 \\
0.4161043 & 0.4161051 \\
0.4161046 & 0.4161053 \\
0.4161046 & 0.4161051 \\
0.4161032 & 0.4161053 \\
0.4161044 & 0.4161052 \\
0.4161045 & 0.4161052 \\
0.4161046 & 0.4161054 \\
0.4161045 & 0.4161045 \\
0.4161046 & 0.4161054 \\
0.4161044 & 0.4161055 \\
0.4161044 & 0.4161054 \\
\hline & \\
\hline & \\
\hline 0 & \\
\hline 0 & \\
\hline 0 & 0.45 \\
\hline
\end{tabular}




\section{Appendix B. Optical Designs for Lambdameters}

The simplest design is a standard Michelson interferometer in which the beams are split at right angles to each other and only one corner cube is scanned. A displacement of the corner cube by some increment $\Delta x$ alters the path difference that light travels through the two arms of the interferometer by $2 \Delta \mathrm{x}$. The number of interference fringes occurring for light of wavelength $\lambda$ is $N \approx 2 \Delta x / \lambda$. Figure $B-1$ shows an equivalent design [5]. A clever folded path design is shown in figure B-2 [7]. Here a displacement of the carriage by a distance $\Delta x$ yields an effective path difference of $4 \Delta x$, so that the number of fringes available for counting is $N \approx 4 \Delta x / \lambda$. In figure $B-3$ a folded path is shown in which each beam is reflected to return upon an identical path to recombine [23]. This can result in unwanted retroreflections into the lasers. A higher order folded-path design is shown in figure B-4. Because very long path differences can impose limits on accuracy, this design is good for decreasing the size of a lambdameter while keeping the resolution constant. A similar design uses mirrors instead of the prism [4]. 


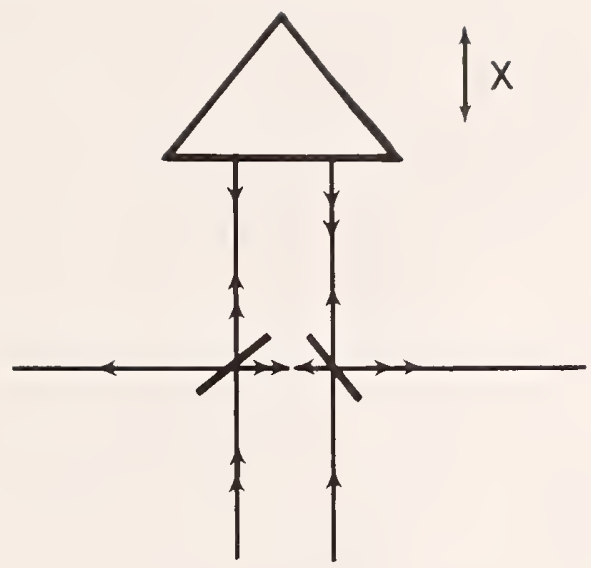

Figure B-1. Kowalski's original wavemeter design [5].

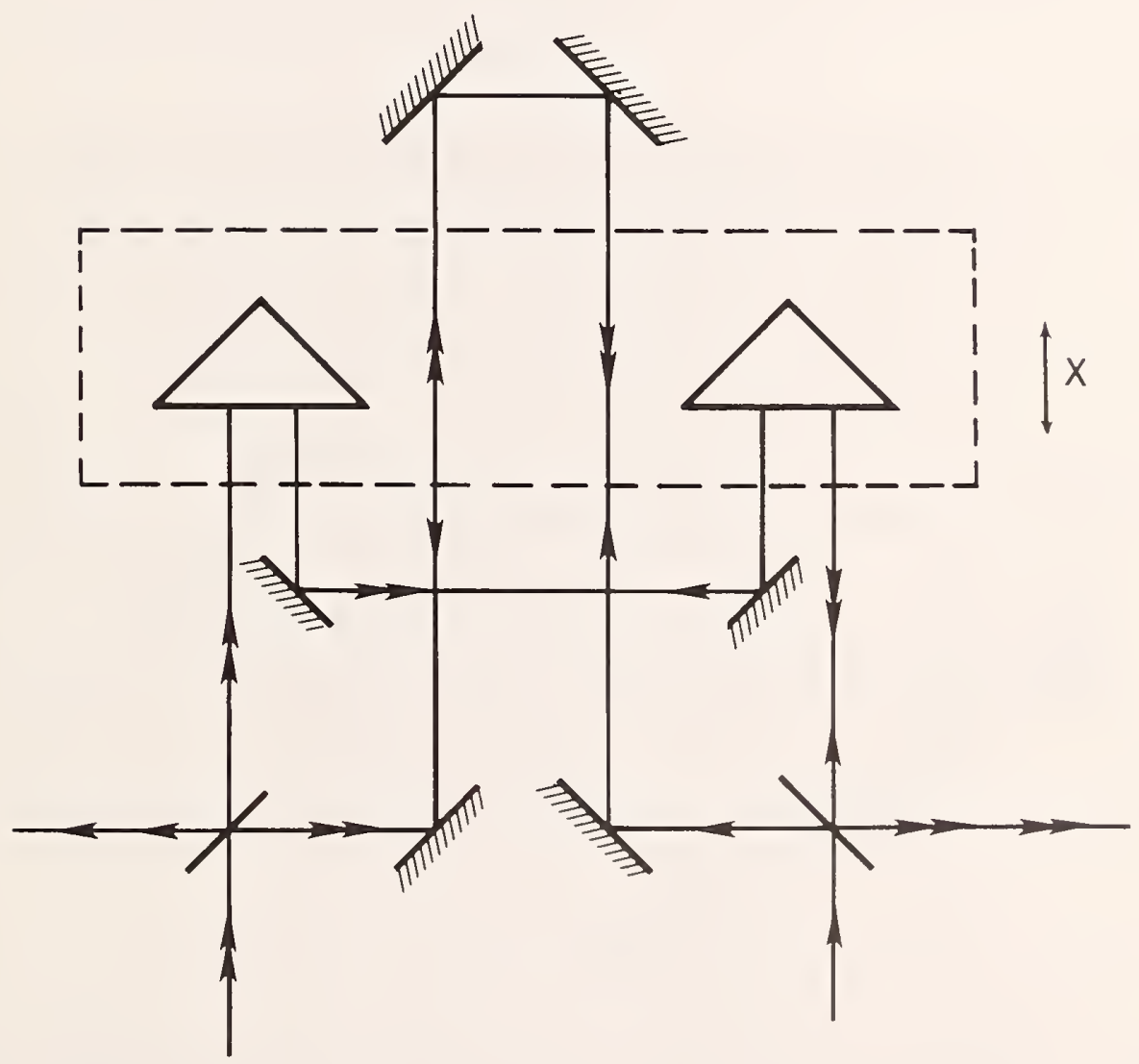

Figure B-2. Kowalski's modified design having a four-fold path [7]. 


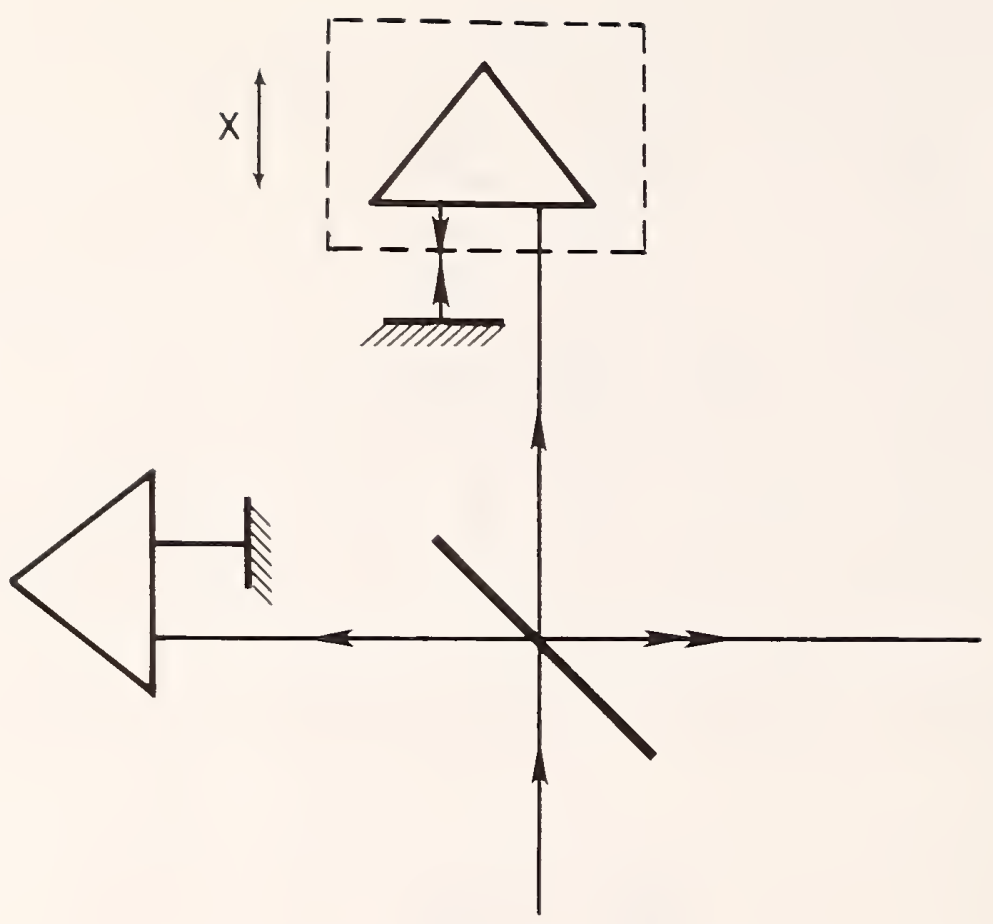

Figure B-3. Wavemeter design showing four-fold path using only one moving corner cube $[22,23]$.
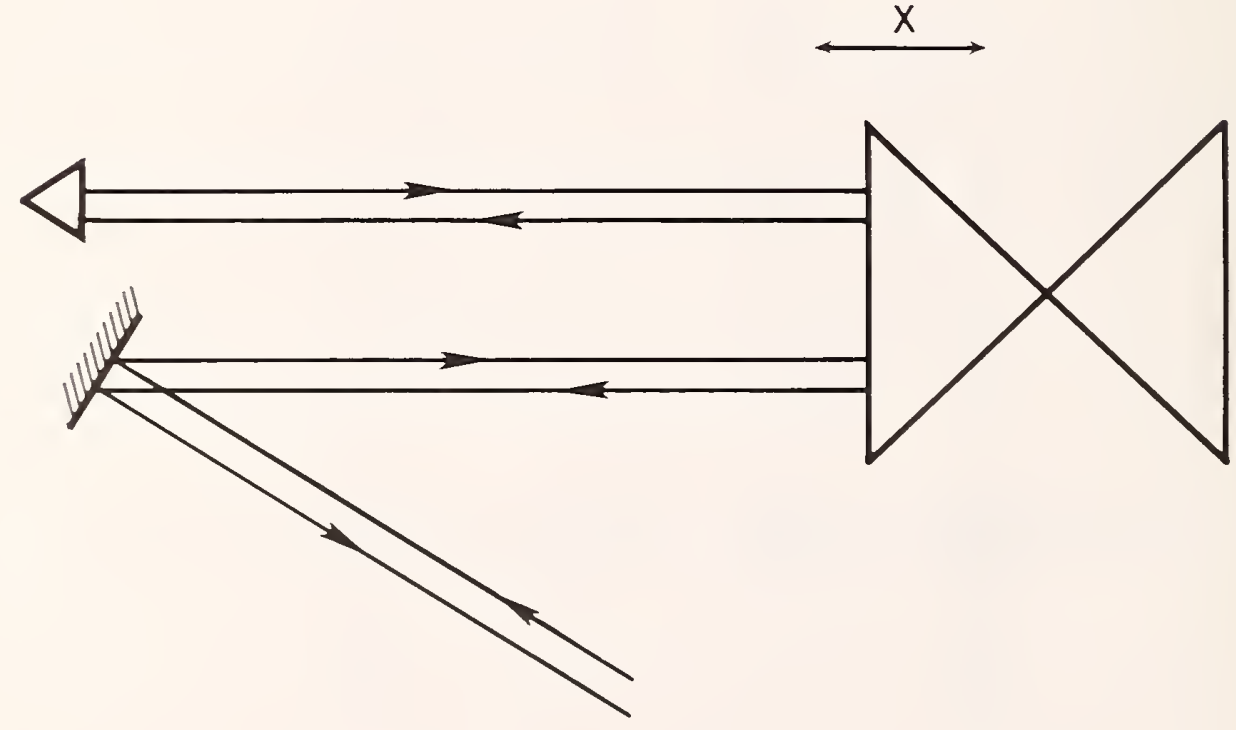

Figure B-4. A modified Hall design with an eight-fold path using a right angle prism and mirror opposite each corner cube. Only the left beam and components are shown. 
Appendix C. First-Generation System

A first-generation wavemeter was built using a linear stepping-motor system with an air bearing for the scanning component. It was rented on a trial basis and tested to determine whether noise and vibration would be low enough to count the fringes from the interferometer. The system consisted of a driver, a $0.66 \mathrm{~m}$ platen, and a forcer that $\mathrm{ran}$ on an air bearing requiring a flow of $14.1 \mathrm{l} / \mathrm{min}$. Air was supplied from the compressor used to float the optical table. The same indexer was used for the final system described in this paper.

The optical arrangement was that of a simple Michelson interferometer that had having two perpendicular arms. The scan distance was $\approx 0.51 \mathrm{~m}$, and the length of the forcer was $\approx 0.15 \mathrm{~m}$. System accuracy was $\approx 1 \mathrm{ppm}$. Fringe signal noise due to vibrations arising from the motion of the forcer over the platen was surprisingly high in spite of the air bearing. Qualitatively, noise was often observed beginning at the third fringe on an oscilloscope screen, but was a function of forcer position along the platen. A different model driver from the same manufacturer was tested, but vibration noise remained high. We decided to look for a system with less noise and greater probability for success at higher accuracies. Although platens of longer length were available for use with air bearing components and which might have increased system accuracy, these were never considered.

The time for a single measurement was $\approx 1$ min. The output from the reference HeNe $(\lambda \approx 0.63 \mu \mathrm{m})$ laser was split and sent into the interferometer along parallel but noncolinear paths. Upon emerging from the interferometer, each fringe signal was sent to its own detector, and the ratio of the numbers of fringes counted during a single scan. A value of 1.000000 was obtained without significant variation. The error was estimated to be $1 / \mathrm{N} \approx 1: 10^{6}$. The output from the DFB laser diode transmitter $(\lambda \approx 1.52 \mu \mathrm{m})$ was compared with the HeNe reference laser. The ratio was found to vary over several parts per million.

A second wavemeter was built using a standard rail table that had $\approx 0.76 \mathrm{~m}$ carriage motion and a Hall optical design. An unstabilized HeNe laser $(\lambda \approx 0.63 \mu \mathrm{m})$ was measured using the same reference laser. Ratio measurements were limited to a few parts per million due to the instability of the test laser. But noise levels were lower than with the previously described linear stepping-motor system. Based on this observation we purchased a precision-grade rail table having a $1.22 \mathrm{~m}$ carriage motion. This was used in the final system, as described in this paper. 
NIST-114A

(REV. 3-89)
U.S. DEPARTMENT OF COMMERCE NATIONAL INSTITUTE OF STANDARDS AND TECHNOLOGY

BIBLIOGRAPHIC DATA SHEET
1. PUBLICATION OR REPORT NUMBER

NIST/TN-1336

2. PERForming ORGAMIZATION REPORT NUMBER

3. PUBLICATION DATE

February 1990

4. TITLE AND SUBTITLE

Wavelength Standard for Optical Fiber Communications

5. AUTHOR(S)

Gregory E. Obarski

6. PERFORMING ORGANIZATION (IF JOINT OR OTHER THAN NIST, SEE INSTRUCTIONS)

U.S. DEPARTMENT OF COMMERCE

NATIONAL INSTITUTE OF STANDARDS AND TECHNOLOGY

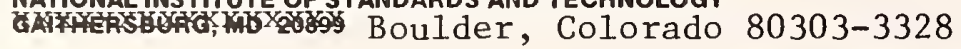

7. CONTRACT/GRANT NUMBER

8. TYPE OF REPORT AND PERIOD COVERED

9. SPONSORING ORGANIZATION NAME AND COMPLETE ADDRESS (STREET, CITY, STATE, ZIP)

10. SUPPLEMENTARY NOTES

DOCUMENT DESCRIBES A COMPUTER PROGRAM; SF-185, FIPS SOFTWARE SUMMARY, IS ATTACHED.

11. ABSTRACT (A 2O0-WORD OR LESS FACTUAL SUMMARY OF MOST SIGNIFICANT INF ORMATION. IF DOCUMENT INCLUDES A SIGNIFICANT BIBLIOGRAPHY OR LITERATURE SURVEY, MENTION IT HERE.)

A wavelength standard in the form of a lambdameter for measurement of single-mode sources used in optical fiber communications is described. The sources of interest are mainly diode laser emitting at 1.3 and $1.5 \mu \mathrm{m}$, but the system can be used in the near IR and red regions of the spectrum. Accuracy in wavelength measurement is verified to be $<0.1 \mathrm{ppm}$ at the $0.63 \mu \mathrm{m}$ HeNe line by comparing separately each of two adjacent modes from a HeNe laser that is frequency-stabilized by a polarization technique, with a single mode from a second similarly frequency-stabilized HeNe laser. Wavelength instability of a commercially packaged $1.52 \mu \mathrm{m}$ distributed-feedback diode laser was measured to be in the range \pm 1 ppm.

12. KEY WORDS (6 TO 12 ENTRIES; ALPHABETICAL ORDER; CAPITALIZE ONLY PROPER MAMES; AMD SEPARATE KEY WORDS BY SEMICOLONS)

diode laser; optical fiber communications; single mode; wavelength instability; wavelength standard 


\section{Periodical}

Journal of Research of the National Institute of Standards and Technology-Reports NIST research and development in those disciplines of the physical and engineering sciences in which the Institute is active. These include physics, chemistry, engineering, mathematics, and computer sciences. Papers cover a broad range of subjects, with major emphasis on measurement methodology and the basic technology underlying standardization. Also included from time to time are survey articles on topics closely related to the Institute's technical and scientific programs. Issued six times a year.

\section{Nonperiodicals}

Monographs-Major contributions to the technical literature on various subjects related to the Institute's scientific and technical activities.

Handbooks-Recommended codes of engineering and industrial practice (including safety codes) developed in cooperation with interested industries, professional organizations, and regulatory bodies. Special Publications-Include proceedings of conferences sponsored by NIST, NIST annual reports, and other special publications appropriate to this grouping such as wall charts, pocket cards, and bibliographies.

Applied Mathematics Series-Mathematical tables, manuals, and studies of special interest to physicists, engineers, chemists, biologists, mathematicians, computer programmers, and others engaged in scientific and technical work.

National Standard Reference Data Series-Provides quantitative data on the physical and chemical properties of materials, compiled from the world's literature and critically evaluated. Developed under a worldwide program coordinated by NIST under the authority of the National Standard Data Act (Public Law 90-396). NOTE: The Journal of Physical and Chemical Reference Data (JPCRD) is published quarterly for NIST by the American Chemical Society (ACS) and the American Institute of Physics (AIP). Subscriptions, reprints, and supplements are available from ACS, 1155 Sixteenth St., NW., Washington, DC 20056.

Building Science Series-Disseminates technical information developed at the Institute on building materials, components, systems, and whole structures. The series presents research results, test methods, and performance criteria related to the structural and environmental functions and the durability and safety characteristics of building elements and systems.

Technical Notes-Studies or reports which are complete in themselves but restrictive in their treatment of a subject. Analogous to monographs but not so comprehensive in scope or definitive in treatment of the subject area. Often serve as a vehicle for final reports of work performed at NIST under the sponsorship of other government agencies.

Voluntary Product Standards-Developed under procedures published by the Department of Commerce in Part 10, Title 15, of the Code of Federal Regulations. The standards establish nationally recognized requirements for products, and provide all concerned interests with a basis for common understanding of the characteristics of the products. NIST administers this program as a supplement to the activities of the private sector standardizing organizations.

Consumer Information Series-Practical information, based on NIST research and experience, covering areas of interest to the consumer. Easily understandable language and illustrations provide useful background knowledge for shopping in today's technological marketplace.

Order the above NIST publications from: Superintendent of Documents, Government Printing Office, Washington, DC 20402.

Order the following NIST publications-FIPS and NISTIRs-from the National Technical Information Service, Springfield, VA 22161.

Federal Information Processing Standards Publications (FIPS PUB)-Publications in this series collectively constitute the Federal Information Processing Standards Register. The Register serves as the official source of information in the Federal Government regarding standards issued by NIST pursuant to the Federal Property and Administrative Services Act of 1949 as amended, Public Law 89-306 (79 Stat. 1127), and as implemented by Executive Order 11717 (38 FR 12315, dated May 11, 1973) and Part 6 of Title 15 CFR (Code of Federal Regulations).

NIST Interagency Reports (NISTIR)-A special series of interim or final reports on work performed by NIST for outside sponsors (both government and non-government). In general, initial distribution is handled by the sponsor; public distribution is by the National Technical Information Service, Springfield, VA 22161, in paper copy or microfiche form. 
U.3. DEPARTMENT OF COMMERCE

National Institute of Standards and Technology

(formerty National Bureau of Standards)

325 Broadway

Boulder, Colorado 80303-3328

OFFICIAL BUSINESS

PENALTY FOR PRIVATE USE, $\$ 00$ 